\title{
Látex de plantas da família Apocynaceae: Uma revisão
}

\author{
Latex of Apocynaceae family plants: A review \\ Látex de plantas de la familia Apocynaceae: Una revisión
}

Recebido: 15/06/2021 | Revisado: 21/06/2021 | Aceito: 23/06/2021 | Publicado: 08/07/2021

\author{
Ana Cristina Oliveira Melo \\ ORCID: https://orcid.org/0000-0002-2835-4754 \\ Universidade Estadual do Ceará, Brasil \\ E-mail: cristinamelo2211@gmail.com \\ Oriel Herrera Bonilla \\ ORCID: https://orcid.org/0000-0002-9140-6086 \\ Universidade Estadual do Ceará, Brasil \\ E-mail: oriel.herrera@uece.br \\ Eliseu Marlônio Pereira de Lucena \\ ORCID: https://orcid.org/0000-0002-8190-1702 \\ Universidade Estadual do Ceará, Brasil \\ E-mail: eliseu.lucena@uece.br
}

\begin{abstract}
Resumo
O látex vegetal é excretado pelo sistema de defesa da planta, em resposta a estresses. Em certos casos, o látex pode apresentar toxicidade, mas sua utilização é viável, pois seus componentes podem possuir atividades biológicas variadas, como: antibacteriana; antitumoral; antioxidante; antifúngica, anti-inflamatório; larvicida, dentre outras. Diferentes famílias botânicas produzem látex, uma das principais e mais abrangente é a Apocynaceae. Diante dessa abrangência, torna-se necessário a realização de estudos sobre a aplicabilidade do látex. Deste modo, o presente estudo teve como objetivo promover a busca por trabalhos científicos que descrevessem sobre o uso do látex das espécies: Calotropis procera (Aiton) W.T. Aiton; Cryptostegia grandiflora R. Br; Cryptostegia madagascariensis Bojer; Hancornia speciosa Gomes; Himatanthus drasticus Mart.; Allamanda blanchetti A. DC. por meio de uma revisão bibliográfica. Os trabalhos científicos foram selecionados sob critérios de exclusão e inclusão, nas bases de dados: "Periódicos CAPES", "Science Direct", "Scielo", "PubMed", "Google Scholar" e "SciFinder" sob um intervalo de tempo de 37 anos (1984-2021), sendo utilizados trabalhos nos idiomas: inglês e português. Os resultados apontam que o látex das espécies, podem atuar como: antimicrobiano, anti-helmíntico, antitumoral, anticâncer, antiinflamatório, quimioterapêutico, larvicida, inseticida, dentre outras atividades. Conclui-se que, o látex vegetal é uma fonte promissora para a síntese de fármacos, repelentes, cosméticos, e pode estimular pesquisas que visem a extração consciente de recursos naturais.
\end{abstract}

Palavras-chave: Espécies laticíferas; Propriedades biológicas; Constituintes químicos.

\begin{abstract}
Plant latex is excreted by the plant's defense system in response to stresses. In certain cases, latex can be toxic, but its use is viable, as its components can have varied biological activities, such as: antibacterial; antitumor; antioxidant; antifungal, anti-inflammatory; larvicide, among others. Different botanical families produce latex, one of the main and most comprehensive is Apocynaceae. Given this scope, it is necessary to carry out studies on the applicability of latex. Thus, this study aimed to promote the search for scientific papers that describe the use of latex species: Calotropis procera (Aiton) W.T. Aiton; Cryptostegia grandiflora R. Br; Cryptostegia madagascariensis Bojer; Hancornia speciosa Gomes; Himatanthus drasticus Mart.; Allamanda blanchetti A. DC. through a literature review. Scientific works were selected under exclusion and inclusion criteria, in the following databases: "CAPES Journals", "Science Direct", "Scielo", "PubMed", "Google Scholar" and "SciFinder" under a time interval of 37 years (1984-2021), being used works in the languages: English and Portuguese. The results show that the latex of the species can act as: antimicrobial, anthelmintic, antitumor, anticancer, anti-inflammatory, chemotherapeutic, larvicide, insecticide, among other activities. It is concluded that plant latex is a promising source for the synthesis of drugs, repellents, cosmetics, and can stimulate research aimed at the conscious extraction of natural resources.
\end{abstract}

Keywords: Lactiferous species; Biological properties; Chemical constituents. 


\begin{abstract}
Resumen
El látex vegetal es excretado por el sistema de defensa de la planta en respuesta al estrés. En ciertos casos, el látex puede presentar toxicidad, pero su uso es viable, ya que sus componentes pueden tener variadas actividades biológicas, tales como: antibacteriano; antitumoral; antioxidante antifúngico, antiinflamatorio; larvicida, entre otros. Diferentes familias botánicas producen látex, una de las principales y más completas es Apocynaceae. Dado este alcance, es necesario realizar estudios sobre la aplicabilidad del látex. Así, el presente estudio tuvo como objetivo promover la búsqueda de artículos científicos que describan el uso del látex en las siguientes especies: Calotropis procera (Aiton) W.T. Aiton; Cryptostegia grandiflora R. Br; Cryptostegia madagascariensis Bojer; Hancornia speciosa Gomes; Himatanthus drasticus Mart .; Allamanda blanchetti A. DC. a través de una revisión de la literatura. Los trabajos científicos fueron seleccionados bajo criterios de exclusión e inclusión, en las siguientes bases de datos: "Revistas CAPES", "Science Direct", "Scielo", "PubMed", "Google Scholar" y "SciFinder" en un intervalo de tiempo de 37 años (1984 -2021), utilizándose obras en los idiomas: inglés y portugués. Los resultados muestran que el látex de la especie puede actuar como: antimicrobiano, antihelmíntico, antitumoral, anticanceroso, antiinflamatorio, quimioterápico, larvicida, insecticida, entre otras actividades. Se concluye que el látex vegetal es una fuente prometedora para la síntesis de fármacos, repelentes, cosméticos y puede estimular la investigación dirigida a la extracción consciente de recursos naturales.
\end{abstract}

Palabras clave: Especies lecheras; Propriedades biológicas; Componentes químicos.

\title{
1. Introdução
}

As plantas apresentam em seus tecidos a presença de metabólitos primários e secundários. Os metabólitos primários são substâncias vitais para o crescimento e desenvolvimento de qualquer planta e podem ser formados por proteínas, ácidos nucléicos e açúcares simples (Santarém et al., 2017). Enquanto que os metabólitos secundários são compostos, que estão associados com as funções protetoras do vegetal, seja contra patógenos (fungos e bactérias), herbívoros (artrópodes), fatores antrópicos, tais como: poluição e ação dos raios ultravioletas (UVs) (Lopez et al., 2012; Morais \& Vieira, 2018). Os metabólitos secundários têm como principais grupos representantes os compostos fenólicos, alcalóides e os terpernóides (Konno, 2011). A presença de cada grupo nas plantas pode ser alterada por diferentes circunstâncias, como: à época do ano, o ritmo circadiano, o fotoperíodo, a sazonalidade, dentre outros fatores (Halfeld-Vieira et al., 2016; Santarém et al., 2017).

Os vegetais podem liberar seus metabólitos por mecanismos estratégicos, conhecidos como exsudados, seja na forma de óleo essencial, goma, resina ou látex (Abarca et al., 2019). Esse último exsudado pode apresentar atividades biológicas variadas, pois sua composição é frequentemente rica em ácidos graxos, hidrocarbonetos, carboidratos, proteínas e metabólitos secundários (Ramos et al., 2011; Silva et al., 2018; D’Abaia et al., 2020). O látex é liberado por meio de dutos lactíferos, essas estruturas podem se fazer presentes em espécies representantes das famílias botânicas: Anacardiaceae, Apocynaceae, Araceae, Asteraceae, Butomaceae, Cactaceae, Euphobiaceae, Fabaceae, Liliaceae, Moraceae, dentre outras (Castro \& Machado, 2006).

A família Apocynaceae se caracteriza pela excreção de látex em abundância e com certas propriedades biológicas conhecidas como, antiparasitárias (Lázaro et al., 2012), antitumoral (Brito et al., 2010), anti-inflamatória (Torres-Rêgo et al., 2016; Marinho et al., 2011), antioxidante (Cunha et al., 2016). Diante desses preceitos da família Apocynaceae, este estudo propõe descrever sobre as aplicabilidades do látex das espécies: Calotropis procera (Aiton) W.T. Aiton; Cryptostegia grandiflora R. Br; Cryptostegia madagascariensis Bojer; Hancornia speciosa Gomes; Himatanthus drasticus Mart.; Allamanda blanchetti A. DC.; por serem plantas que crescem de forma natural em diversos tipos de solos e ambientes do nordeste brasileiro.

\section{Metodologia}

Esta revisão bibliográfica é de cunho qualitativo, no qual visa a apresentação de dados secundários que possam ter relevância para a área do estudo. Reunindo contribuições de diferentes pesquisas, mas tendo o cuidado no direcionamento 
sobre quais informações possam ter relação com o foco do trabalho (Köche, 2011). Sendo assim, para a efetuação desta revisão, foram consultadas diferentes referências na literatura, de modo a conceder uma busca organizada por dados científicos referentes a utilidade do látex vegetal de cada espécie mencionada, e quais compostos constituintes poderiam estar associados com as propriedades biológicas exibidas. A pesquisa utilizou as seguintes palavras-chave: "latex Calotropis procera", "latex Cryptostegia grandiflora". "latex Cryptostegia madagascariensis", "latex Hancornia speciosa", "latex Himatanthus drasticus", "latex Allamanda". A busca por estudos ocorreu nos bancos de dados: Periódicos CAPES (http://www.periodicos.capes.gov.br/), Science Direct (https://www.sciencedirect.com/), Scielo (https://scielo.org/), PubMed (https://pubmed.ncbi.nlm.nih.gov/), Google Scholar (https://scholar.google.com.br/) e SciFinder (https://scifinder.cas.org/). As informações taxonômicas foram consultadas no site Flora do Brasil (2020) (http://floradobrasil.jbrj.gov.br/reflora/floradobrasil/FB48). O intervalo de tempo foi de 37 anos para publicações compreendidas entre março de 1984 a março de 2021, essa escala de tempo foi usada em decorrência da baixa existência de estudos com a Cryptostegia madagascariensis. Foram utilizados trabalhos nos idiomas inglês e português. Sob o estabelecimento de critérios, constituíram incluídas publicações que abordassem sobre o uso do látex vegetal de alguma das espécies pesquisadas e estudos que relatassem sobre as propriedades biológicas. Entretanto, foram excluídos trabalhos que não evidenciavam a relevância de estudos com as espécies pesquisadas ou que não abordavam os princípios ativos presentes nelas.

\section{Resultados e Discussão}

\subsection{Família Apocynaceae}

A família botânica Apocynaceae foi descrita com o nome Apocineae em Genera Plantarum (1798), por Antonie Laurent de Jussieu, o autor classificou a família na ordem Gentianales, subclasse Asteridae (Coutinho, 2017). Apocynaceae permanece na ordem Gentianales, sendo considerada como uma das maiores famílias botânicas de angiospermas, detém aproximadamente 400 gêneros e 3700 espécies (Souza \& Lorenzi, 2019). No Brasil, a quantidade de espécies Apocynaceae nativas corresponde a 91 gêneros, 808 espécies, 10 subespécies e 26 variedades (Flora Brasil, 2020).

As espécies Apocynaceae são caracterizadas pela produção de látex (Rapini, 2012), adicionalmente, apresentam características diversificadas, podem ser arbustos, subarbustos eretos, trepadeiras, lianas, árvores, ervas ou latescentes (Wanderley et al., 2005; Rapini, 2000; Souza \& Lorenzi, 2019). As representantes de Apocynaceae possuem ampla distribuição, frequentemente são encontradas em regiões tropicais, mas podem ocorrer em áreas temperadas (Souza \& Lorenzi, 2019). As espécies da família têm ampla utilidade, desde a construção civil, medicina popular (Lorenzi, 1997; Machete et al., 2016), ornamentação (Maia-Silva et al., 2012) e alimentação (Assumpção et al., 2014; Júnior et al., 2017). No entanto, deve-se destacar que nem todas as espécies de Apocynaceae podem ser utilizadas para alimentação humana ou para ornamentação, pois algumas plantas são tóxicas para animais e seres humanos (Rebouças Filho et al., 2021; Medeiros et al., 2019; Sousa et al., 2016; Vieira et al., 2004).

Na Tabela 1 descrevemos as características referentes ao látex produzido pelas plantas pesquisadas, e informações vinculadas à forma de vida, preparação do látex (como o látex foi utilizado), compostos bioativos do metabolismo primário, constituintes do metabolismo secundário, atividades biológicas e referências. 
Tabela 1. Espécies lactíferas da família botânica Apocynaceae que tiveram o látex investigado.

\begin{tabular}{|c|c|c|c|c|c|c|}
\hline Nome cientifico & $\begin{array}{c}\text { Forma de } \\
\text { vida }\end{array}$ & $\begin{array}{c}\text { Preparação } \\
\text { do látex }\end{array}$ & $\begin{array}{c}\text { Compostos } \\
\text { bioativos do } \\
\text { metabolismo } \\
\text { primário }\end{array}$ & $\begin{array}{c}\text { Constituintes } \\
\text { do } \\
\text { metabolismo } \\
\text { secundário }\end{array}$ & $\begin{array}{c}\text { Atividades } \\
\text { biológicas }\end{array}$ & Referências \\
\hline $\begin{array}{l}\text { Calotropis procera } \\
\text { (Aiton) W. T. Aiton } \\
\text { Algodão-de-seda }\end{array}$ & Arbusto & $\begin{array}{l}\text { Isolamento de } \\
\text { proteínas, } \\
\text { extrato } \\
\text { metanólico, } \\
\text { extrato } \\
\text { glicosidal } \\
\text { cardíaco, látex } \\
\text { purificado, } \\
\text { fração de: } \\
\text { hexano, } \\
\text { acetato de } \\
\text { etila, metanol, } \\
\text { e extrato } \\
\text { aquoso }\end{array}$ & $\begin{array}{l}\text { Protease de } \\
\text { cisteína } \\
(\mathrm{CpCP} 3), \\
\text { proteínas } \\
\text { lactíferas de } \\
\text { modo geral, } \\
\text { subfrações } \\
\text { proteicas (LP, } \\
\text { LP II, LP III), } \\
\text { peptidases LPp2 }\end{array}$ & $\begin{array}{l}\text { Fenóis, } \\
\text { esteróides, } \\
\text { alcalóides, } \\
\text { glicosídeos } \\
\text { cardíacos, ácido } \\
\text { gálico, } \\
\text { quercetina, } \\
\text { flavonas, } \\
\text { flavonóis, } \\
\text { xantonas, } \\
\text { flavononóis, } \\
\text { urs-19(29)-em- } \\
\text { 3-il acetato, ß- } \\
\text { sitosterol, } \\
\text { estigmasterol, } \\
\text { multiflorenol, } \\
\text { urs-19(29)-em- } \\
\text { 3-ß-ol, 3ß,27- } \\
\text { dihidroxi-urs- } \\
\text { 18-em-13,28- } \\
\text { olide acetil urs- } \\
\text { 19(29)-em-3-il, } \\
\text { (3ß)-Urs- } \\
\text { 19(29)-em-3-ol } \\
\text { e 1-(2',5'- } \\
\text { dimetoxifenil)- } \\
\text { glicerol }\end{array}$ & $\begin{array}{l}\text { Produção de } \\
\text { queijo, } \\
\text { antimicrobiano, } \\
\text { depilatório, anti- } \\
\text { helmíntico, } \\
\text { antitumoral, } \\
\text { anticâncer, anti- } \\
\text { inflamatório, } \\
\text { quimioterpêutico, } \\
\text { antibacteriano, } \\
\text { larvicida, } \\
\text { inseticida, } \\
\text { antifúngico }\end{array}$ & $\begin{array}{l}\text { Silva et al., } \\
\text { (2019), López et } \\
\text { al., (2017), } \\
\text { Kumar et al., } \\
\text { (2019), } \\
\text { Cavalcante et al., } \\
\text { (2020), Choedon } \\
\text { et al., (2006), Al- } \\
\text { Qahtani et al., } \\
\text { (2020), Sousa et } \\
\text { al., (2020), } \\
\text { Tavares et al., } \\
\text { (2021), Ramos et } \\
\text { al., (2009), } \\
\text { Mohamed \& Said } \\
\text { (2020), Freitas et } \\
\text { al., (2016), } \\
\text { Chundattu et al., } \\
\text { 2016, Cavalcante, } \\
\text { 2015. }\end{array}$ \\
\hline $\begin{array}{l}\text { Harconia speciosa } \\
\text { Gomes } \\
\text { Mangabeira }\end{array}$ & Árvore & $\begin{array}{l}\text { Puro, fração } \\
\text { aquosa }\end{array}$ & $\begin{array}{l}\text { Proteínas no } \\
\text { geral, } \\
\text { aminoácidos }\end{array}$ & $\begin{array}{l}\text { Borracha, ácido } \\
\text { clorogênico, } \\
\text { maringenina-7- } \\
\text { O-glicosídeo, } \\
\text { rutina, } \\
\text { catequina, } \\
\text { procianidina }\end{array}$ & $\begin{array}{l}\text { Antioxidante, } \\
\text { antibacteriano, } \\
\text { anti-inflamatório, } \\
\text { osteogênico, } \\
\text { angiogênico, anti- } \\
\text { biofilme, } \\
\text { cicatrizante, } \\
\text { atóxico. }\end{array}$ & $\begin{array}{l}\text { Pinheiro; Pinheiro } \\
\text { (2009), Júnior et } \\
\text { al., (2017), } \\
\text { D’Abadia et al., } \\
\text { (2018), Junior et } \\
\text { al., (2010), } \\
\text { Marinho et al., } \\
\text { (2011), D’Abadia } \\
\text { et al., (2020), } \\
\text { Neves et al., } \\
\text { (2016), Neves et } \\
\text { al., (2014), } \\
\text { Almeida et al., } \\
\text { (2019), Bonete et } \\
\text { al., (2020), } \\
\text { Ribeiro et al., } \\
\text { (2016). }\end{array}$ \\
\hline $\begin{array}{l}\text { Himatanthus } \\
\text { drasticus (Mart.) } \\
\text { Plumel } \\
\text { Janaguba }\end{array}$ & Árvore & $\begin{array}{l}\text { Puro, diluído } \\
\text { em água, } \\
\text { isolamento de } \\
\text { metabólitos } \\
\text { primários e } \\
\text { secundários }\end{array}$ & $\begin{array}{l}\text { Proteína solúvel } \\
\text { HdLP }\end{array}$ & $\begin{array}{l}\text { Esteroides, } \\
\text { saponinas, } \\
\text { monoterpenos, } \\
\text { sesquiterpenostr } \\
\text { iterpenos } \\
\text { (lupeol, a- } \\
\text { amirina, ß- } \\
\text { amirina, acetato } \\
\text { de lupeol), } \\
\text { fenóis, } \\
\text { flavonoides, } \\
\text { iridoides } \\
\text { glicosilados, a- } \\
\text { etil glucosídeo, } \\
\text { ácido } \\
\text { prototecuico, }\end{array}$ & $\begin{array}{l}\text { Antibiofilme, } \\
\text { antibacteriano, } \\
\text { antinociceptivo, } \\
\text { anti-inflamatório, } \\
\text { anticulcergêncioc } \\
\text { o, antitumoral, } \\
\text { antidiabético }\end{array}$ & $\begin{array}{l}\text { Moura et al., } \\
\text { (2019), Moura et } \\
\text { al., (2016), } \\
\text { Almeida et al., } \\
\text { (2016), Soares et } \\
\text { al., (2008), Moura } \\
\text { et al., (2020), } \\
\text { Lucetti et al., } \\
\text { (2010), Colares et } \\
\text { al., (2008), Santos } \\
\text { et al., (2018), } \\
\text { Mousinho et al., } \\
\text { (2011), Morais et } \\
\text { al., (2020). }\end{array}$ \\
\hline
\end{tabular}



ácido 3-O-
cafeoilquínico, ácido 15- desmetilplumier
ida, ácido 5-O- cafeoilquínico, ácido cafeíco, ácido vanílico plumieride

\begin{tabular}{lllll}
\hline $\begin{array}{l}\text { Cryptostegia } \\
\text { grandiflora }(\mathrm{R} . \mathrm{Br} .)\end{array}$ & Arbusto & $\begin{array}{l}\text { Extração e } \\
\text { isolamentos } \\
\text { de proteínas }\end{array}$ & $\begin{array}{l}\text { Proteínas } \\
\text { lactíferas de } \\
\text { modo geral, } \\
\text { proteína cisteína } \\
\text { peptidases }\end{array}$ & $\begin{array}{l}\text { Polifenóis, } \\
\text { triglicerídeos,hi } \\
\text { drocarbonetos, } \\
\text { glisosídeos } \\
\text { cardíacos. }\end{array}$
\end{tabular}

Cryptostegia madagascariensis Bojer

Extrato
etanólico,
extrato
hexânico,
isolamento de
compostos

Cardenólidos, fenóis, taninos, flavononóis flavonas,

flanonois, xantonas, alcalóides, esteróides, triterpenos, ácido gálico, rutina3-

hidroxihexadeca noato de metila, 3-

hidroxioctadeca noato de metila

\author{
Anti-inflamatório, Freitas et al., \\ antifúngico, (2010), Ramos et \\ depilatório, al., (2014), \\ fibrinogenolitico, Freitas et al., \\ edematogênico, (2015), López et \\ larvicida, al., (2017), Viana \\ moluscicida et al., (2013), \\ Albuquerque et \\ al., (2009), \\ Ramos et al., \\ (2009), Kamelia \\ et al., 2011
}

Sanduja et al., Antioxidante, $\quad$ (1984), Pinheiro antiacetilcolinestr ase et al, (2021)

\begin{tabular}{|c|c|c|c|c|c|}
\hline $\begin{array}{l}\text { Allamanda } \\
\text { blanchetti A. DC. } \\
\text { Sete-patacas-roxa }\end{array}$ & Arbusto & $\begin{array}{l}\text { Látex diluído } \\
\text { em água }\end{array}$ & 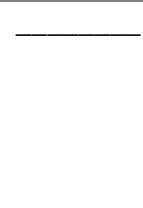 & $\begin{array}{l}\text { Laxante, emético, } \\
\text { catártico, } \\
\text { problemas } \\
\text { cardíacos, } \\
\text { hipertensão }\end{array}$ & $\begin{array}{l}\text { Agra et al., } \\
\text { (2007), } \\
\text { Albuquerque et } \\
\text { al., (2007) }\end{array}$ \\
\hline
\end{tabular}

Fonte: Autores (2021).

Dentre as plantas pesquisadas, percebeu-se que todas apresentam relatos de princípios ativos, desde extratos de partes aéreas (folhas, frutos e flores), raízes, cascas, até o látex em si. Em relação ao uso do látex, Calotropis procera, foi a espécie mais citada nos estudos encontrados nesta revisão. Deve-se salientar que as outras espécies também apresentaram características promissoras, com propriedades anti-inflamatórias, anticâncer, antioxidante, antiparasitária, antimicrobiana, larvicida, inseticida, potencial osteogêncio, dentre outras especificações. As descrições acerca das atividades biológicas exercidas pelas espécies seguem adiante na forma de tópicos. 


\subsubsection{Calotropis procera (Aiton) W. T. Aiton}

Calotropis procera, conhecida popularmente como "Akumd" na Índia, e por "Algodão-de-seda" no Brasil, dentre outros nomes conforme o país, é um arbusto de origem asiática, mas com ampla distribuição em regiões quentes e tropicais, por sua fácil adaptação a solos poucos produtivos tem se tornado uma planta invasora em países, como: Austrália, Caribe, e no Nordeste do Brasil (Instituto Hórus, 2021). Entretanto, é uma espécie bastante utilizada, desde a ornamentação a medicina popular.

Extratos vegetais de acetato de etila, acetona e metanol feitos a partir do caule de $C$. procera exibiram atividade antiproliferativa ao serem testados in vitro em células cancerígenas, do tipo Sarcoma 180 (Magalhães et al., 2010). Enquanto que, o extrato aquoso da raiz de C. procera em uma concentração de $3 \mathrm{mg}$ demostrou efeito quelante de $93 \%$ em íons metálicos, observou-se atividade na eliminação de radicais livres, nas análises fitoquímicas feitas foram identificados a presença de taninos ou flavonóides (Kumar et al., 2013). Sabe-se que ambos os metabólitos secundários podem atuar como agentes antioxidantes (Morais \& Vieira, 2018; Morais et al., 2021).

Em relação as propriedades anticâncer, ao ser feito uso da análise cromatográfica do extrato metanólico do látex de C. procera foram geradas 11 frações, dessas a fração 8, exibiu mecanismos de ação contra células cancerosas em fígados de camundongos (Choedon et al., 2006). Em outro estudo, ao ser isolado um extrato de glicosidal cardíaco do látex de C. procera, e testado em células cancerígenas de mamas, observou-se que o isolado exerceu citotoxicidade, indução a apoptose e autofagia (Al-Qahtani et al., 2020).

Além de conter propriedades anticâncer, o látex exibiu potencial depilatório (Lopéz et al., 2017). Assim como, foi ativo na produção de lacticínios, uma vez que ao usarem uma protease de cisteína (CpCP3) do látex de C. procera, em substituição a quimosina bovina, para produção de queijos notou-se que a protease desempenhou um mecanismo parecido com a quimiosina, entretanto a CpCP3 proporcionou maior suavidade aos queijos produzidos (Silva et al., 2019). As proteínas do látex também podem exercer ação quimioterapêutica, ao testarem uma fração proteica do látex em hamsters, e induzirem mucosite nos animais, Freitas et al., (2012) observaram que os roedores que receberam a fração proteica exibiram redução do nível de infiltração de células inflamatórios, significando que o látex pôde ter inibido mediadores inflamatórios, tais como fator de necrose tumoral alfa (TNF-a), interleucina-1ß (IL-1ß), ciclooxigenase-2 (COX-2) e síntese de óxido nítrico induzível (iNOS). Um estudo com cisteinas peptidases do látex de C. procera (LPp2) demonstrou atividades anti-inflamatórias, ao serem testadas contra Salmonella spp., um gênero bacteriano que afeta o sistema gastrointestinal, ocasionando febre tifóide e paratifóide, gastroenterite, dentre outros efeitos que atingem animais e humanos, observou-se que LPp2 influenciou na indução de macrófagos produzissem compostos microbicidas, como o óxido nítrico (NO) (Tavares et al., 2021). A partir de uma fração proteica do látex de C. procera (LP) foram produzidas subfrações (LP II e LPIII) e aplicadas em camundongos, que na sequência foram infectados com Salmonella enterica (ex Kauffmann \& Edwards 1952) Le Minor \& Popoff 1987, observou-se que possivelmente os constituintes de LP exerceram efeito sinérgico, enquanto a fração LPIII exibiu melhor efeito contra Salmonella, uma vez que protegeu 70\% dos camundongos contra a bactéria, segundo os autores, a fração LPIII era composta por quatro proteínas principais distinguíveis, os dados sugerem uma investigação mais aprofundada (Sousa et al., 2020). Em outro estudo conduzido com um isolado de látex de C. procera contra E. coli e Salmonella enterica, verificou-se que a proteína isolada exibiu maior atividade em $\mathrm{pH} 7$, diante do obtido, foi proposto a necessidade a realização de outros estudos afim de descobrir mais afundo sobre quais proteínas estariam envolvidas com os mecanismos antimicrobianos desempenhados (Kumar et al., 2019).

Quando testado o efeito antibacteriano, por meio da técnica de microdiluição em caldo, das frações de hexano, acetato de etila, metanol e água do extrato do látex de C. procera contra as linhagens bacterianas: Staphylococcus aureus Rosenbach (1884), Proteus vulgaris Hauser (1885), Pseudomonas aeuroginosa Schroeter (1872), Vibrio cholorease Pacini (1854) e 
Escherihia coli T. Escherich (1885), obteve-se que a fração aquosa do látex foi a mais efetiva, em especial contra $P$. aeuroginosa (CIM $128 \mu \mathrm{g} / \mathrm{mL}$ ) enquanto as frações acetato e metanólica exibiram maior efeito citotóxico em Artemia salina Linnaeus (1758), a investigação fitoquímica do látex exibiu a presença de flavonas, flavonóis, xantonas, flavononóis, esteroides e alcalóides (Brito et al., 2010).

Como agente larvicida frente ao Aedes aegypti L. o látex de C. procera indicou a existência de compostos tóxicos nos fluidos lactíferos (Ramos et al., 2009). Em relação a atividade inseticida, pôde afetar ninfas de Locusta migratoria L. (Orthoptera), gafanhoto africano (Mohamed \& Said, 2020). Enquanto que a presença de proteínas quitinases, no látex, atuaram contra Callosobruchus maculatus (Bruchidae) Fabricicus (1775) e inibirem o crescimento de hifas dos fungos fitopatogênicos: Fusarium oxysporum Link ex Grey (1821) e Colletotrichum gloesporioides (Penz. e Sacc.) fungo causador de antracnose, uma doença que ocasiona baixa produção de frutos pelo vegetal (Freitas et al., 2016).

Os constituintes químicos do látex de C. procera têm demonstrado efeitos anti-helmínticos contra Haemachus contortus Rodolphi (1803), um nematoide parasita de ruminantes. Duas frações do látex de C. procera, uma fração não contendo proteínas (LNP) e outra fração rica em proteínas (LP) foram testadas in vitro contra Haemachus contortus, obteve-se que ambas as frações foram responsáveis por afetarem a cutícula dos nematoides, a investigação feita no estudo revelou os seguintes compostos: fenóis, esteroides, alcalóides e glicosídeos cardíacos, e a análise na cromatografia líquida de alta eficiência (HPLC), identificou com a presença de ácido gálico e quercetina (Cavalcante et al., 2020). Sabe-se que o látex de $C$. procera é rico em esteróis, tais como: urs-19(29)-em-3-il acetato, ß-sitosterol, estigmasterol, multiflorenol, urs-19(29)-em-3-ßol, 3ß,27-dihidroxi-urs-18-em-13,28-olide (Chundattu et al., 2016). Em um extrato de acetato de etila do látex de C. procera foram isolados; acetil urs-19(29)-em-3-il, (3ß)-Urs-19(29)-em-3-ol e 1-(2',5'- dimetoxifenil)- glicerol (Cavalcante, 2015).

\subsubsection{Harconia speciosa Gomes}

Harconia speciosa Gomes, conhecida como "Mangabeira", é a única espécie do gênero Harconia, árvore nativa no Brasil, com ocorrência nos países Bolívia, Peru e Paraguai (Lêdo et al., 2015). Na culinária brasileira, seus frutos podem ser consumidos naturalmente ou utilizados na indústria alimentícia para fabricação de sucos, doces, sorvetes, dentre outras alternativas, enquanto que a madeira pode ser utilizada na construção civil (Assumpção et al., 2014; Júnior et al., 2017).

O látex de H. speciosa representou uma importante fonte de renda para famílias que viviam à base do extrativismo vegetal durante o ciclo da borracha no Brasil, uma vez que o látex de $H$. speciosa foi uma das matérias-primas mais visadas para comercialização (Lêdo et al., 2015; Junior et al., 2017). A obtenção do látex acontece por meio de incisões feitas no caule, sua forma de extração é parecida com a Hevea brasiliensis L., seringueira (Arruda et al., 2016).

Uma caracterização química do extrato etanólico das folhas de H. speciosa identificou a presença de vinte e oito compostos, dentre os quais foram exibidos compostos com propriedades antidiabéticas, como flavonóis, quercentina e Kaempferol (Bastos et al., 2017). Em outro estudo feito com o extrato etanólico provindo dos frutos de H. speciosa foram exibidos a presença de fenóis, flavonóides e taninos, esses dados sugerem que os frutos podem ter atividade antioxidante, o que reforça o direcionamento de mais estudos aprofundados (Assumpção et al., 2014).

Assim como folhas e frutos apresentam princípios ativos, o látex de H. speciosa oferece propriedades biológicas. Ao ser estudado os efeitos antioxidante e antibacteriano de uma fração aquosa do látex de $H$. speciosa, notou-se que o potencial antioxidante da fração aquoso ( $\mathrm{IC}_{50}=76,52 \mathrm{mg} / \mathrm{mL}$ ) aumentava conforme a concentração do látex, resultando na eliminação dos radicais livres, na caracterização química feita por cromatografia a líquido de alta eficiência foi identificado a presença do ácido clorogênico, o qual pôde ser relacionado com a atividade antioxidante, entretanto a fração não demostrou eficácia contra Escherichia coli e Staphyloccoccus aureus (D’Abadia et al., 2018). Em contrapartida, outra pesquisa conduzida com o látex de 
H. speciosa observou que o látex diluído em água destilada não exibiu efeito sobre Staphyloccoccus aureus, mas pôde afetar o crescimento de Escherichia coli, enquanto que frações de látex puro exerceu inibição nas duas cepas (Junior et al., 2018).

A busca por princípios ativos contra doenças inflamatórias, dentre outras, incentiva pesquisas na área da prospecção fitoquímica para produção de produtos naturais (Morais \& Vieira, 2018). Alguns desses estudos estão sendo conduzidos com o látex da mangabeira, foi demostrado que o látex $(0,06-1,3 \mathrm{mg} / \mathrm{kg})$ teve a capacidade de reduzir a produção de interleucina-6 (IL-6), TNF, NO e prostaglandina E2 (PGE2) (Marinho et al., 2011). Sabe-se que outras partes da H. speciosa, como um extrato aquoso dos frutos, exibiu propriedades anti-inflamatórias, pois reduziu a migração de leucócitos no modelo in vivo, essa ação foi associada com a presença de rutina e ácido clorogênico, compostos que foram identificados no estudo (TorresRêgo et al., 2016).

Ao ser avaliado o potencial osteogêncio e citoxicidade da fase aquosa do látex de H. speciosa em células calvárias de ratos, obteve-se que houve proliferação celular do periósteo e formação óssea in vivo na presença do látex, a análise em espectrometria de massa sugeriu: catequina, procianidina, ácido clorogêncio e maringenina-7-O-glicosídeo, esses dois últimos compostos receberam a atribuição dos efeitos da fase aquosa do látex (Neves et al., 2016). No entanto, quando utilizado baixas concentrações oralmente de látex de $H$. speciosa o processo de neoformação e mineralização óssea em ratos Wistar não exibiu efeitos significativos para promover o aumento da capacidade de regeneração óssea, os autores relataram que os dados obtidos podem ter relação com o método de administração (Fellipetti et al., 2019).

Quando avaliado a atividade angiogênica do látex de H. speciosa usando membrana corioalantóide de pintinhos (CAM) notou-se que o látex estimulou os processos de angiogênese e remodelação da matriz extracelular, a análise química indicou a presença de ácidos clorogênicos como os principais compostos encontrados na amostra de látex (D'Abadia et al., 2020). Um ensaio in vitro com Alluim cepa L., cebola, a respeito de uma investigação do nível de citotoxicidade e genotoxicidade, o látex de $H$. speciosa não exerceu efeitos inibitórios e citotóxicos nas células meristemáticas de $A$. cepa (Ribeiro et al., 2016).

Ao testarem o látex de $H$. speciosa como biomembrana para liberação controlada de nanopartículas de prata, ressaltou-se que ocorreu a estabilização e acomodação das nanopartículas de prata, os efeitos foram associados a presença de aminoácidos e proteínas presentes no látex, mas a parte cis-isopreno do látex, que seria a borracha natural, deteve as nanopartículas (Almeida et al., 2019). Em outro estudo, no qual o látex da planta foi incorporado a nanopartículas de prata, percebeu-se a exibição da atividade angiogênica e aceleração na regeneração celular, os estudiosos complementaram que o biomaterial demonstrou bons resultados na cicatrização de feridas cutâneas (Bonete et al., 2020).

\subsubsection{Himatanthus drasticus (Mart.) Plumel}

O gênero Himatanthus é composto por nove espécies encontradas em regiões tropicais e subtropicais, uma das representantes é Himatanthus drasticus (Mart.) Plumel, conhecida popularmente como "Janaguba", é uma árvore endêmica no Brasil, com distribuição pelo Norte, Nordeste, Centro-Oeste e Sudeste do país (Flora do Brasil, 2020). Na medicina popular são utilizados cascas e látex, esse último é misturado com água para obtenção de "leite de janaguba" (Lucetti et al., 2010).

As cascas de H. drasticus são utilizadas por criadores de ruminantes como tratamento verminose, por essa razão um extrato hidroalcóolico e seus subextratos de hexano, acetato de etila, butanol e aquoso foram investigados, a prospecção fitoquímica, a coluna cromatográfica (CC) e a cromatográfica em camada delgada (CDD) sugeriram a existência de taninos, alcalóides, flavonóides, fenóis, triterpernóides e cumarinas, os dados possibilitam uma investigação mais aprofundada (Luz et al., 2014). No conhecimento etnofarmacalógico, o látex de H. drasticus é coletado em um horário cedo da manhã, após sua extração pode ser utilizado como fonte curativa, preventivo ou atuar em cuidados paliativos, sendo utilizado nos casos: úlcera, inflamação, câncer, diabetes, gastrite, reumatismo, hemorroida, disjunção erétil, mioma, pano branco e tratamento na vesícula (Soares et al., 2016; Colares et al., 2008). 
Diante da abrangência de relatos para o uso látex de H. drasticus, estudos continuam sendo feitos. Em um ensaio foi comprovado o efeito antibiofilme do látex de H. drasticus contra as bactérias Pseudomonas aeroginosa e Staphylococcus aureus, os autores propuseram a execução de novos estudos elucidativos (Moura et al., 2019). Enquanto que, a microdiluição do látex de H. drasticus em caldo exibiu atividade antibacteriana frente de Acinetobacter baumanii Bouver \& Grimont (1986) e Escherichia coli, em soma demostrou ser antimutagênico, em complemento, a análise na cromatografia em camada delgada, identificou a presença de esteroides, saponinas, monoterpenos, sesquiterpenos e triterpenos, entretanto não houve isolamento de compostos para descobrir quais moléculas estariam presentes no desencadeamento da ação antibacteriana (Moura et al., 2016).

Estudos com o látex de $H$. drasticus corroboram a existência de triterpenos com propriedades biológicas. Testes fitoquímicos com o látex liofilizado de $\mathrm{H}$. drasticus constataram a presença de dezesseis compostos, sendo que os compostos principais foram: acetato de lupeol, betulina, a-aminina, $\beta$-aminina (Moura et al., 2020). Derivados de triterpenos: lupeol, aamirina e $\beta$-amirina, presentes no látex de $\mathrm{H}$. drasticus demostraram efeito antinociceptivo e anti-inflamatório, ao inibirem o estresse oxidativo expresso por enzimas inflamatórias, citocinas pró-inflamatórias e agentes inflamatórios, como TNF-a, histona deacetilase (HDAC) e fator nuclear kappa B (NF-KB) (de-Almeida et al., 2019). Ao isolarem o acetato de lupeol presente no látex de $H$. drasticus e testá-lo foi percebido atividade anti-inflamatória pela redução no número de células que expressavam iNOS (Lucetti et al., 2010). O látex de H. drasticus $(0,4$ e 0,2 $\mathrm{mL} / 10 \mathrm{~g})$ usado com antecedência a indução de lesões gástricas por etanol e indomentacina em camundongos, comprovou que houve redução no nível das lesões gástricas e exibiu efeito anticulcergênico, ao inibir a biossíntese de prostaglandinas, essas respostas foram associadas com a presença de triterpenos no látex, tais evidências ressaltam a importância de mais estudos (Colares et al., 2008).

Um tratamento em células cancerígenas com o látex de $H$. drasticus demonstrou redução nas expressões emitidas por linfócitos $\mathrm{T}$, mais especificamente os subconjuntos $\mathrm{CD} 4^{+}$e $\mathrm{CD} 8^{+}$, os autores associaram o efeito anticâncer a presença dos triterpenos: a-amirina, B-amirina e cinamato de lupeol (Santos et al., 2018). No entanto, camundongos que receberam um tratamento com o látex de $H$. drasticus, na sequência houve a indução de câncer de pulmão por uretana, não apresentaram resultados promissores para afirmarem o efeito antitumoral exercido pelo látex (França et al., 2011).

O metabolismo primário do látex de H. drasticus tem exibido princípios ativos, ao dialisarem o látex de $H$. drasticus e obterem uma proteína solúvel (HdLP) avaliou-se o desempenho da atividade antitumoral in vivo em camundongos que receberam os modelos tumorais sarcoma 180 e carcinossarcoma Walker 256, constatou-se que a proteína reduziu o crescimento dos tumores, essa resposta teria associação com as propriedades imunomoduladoras da proteína, a qual não exibiu efeito citotóxico in vitro (Mousinho et al., 2011).

Ao elaborarem três frações do látex de H. drasticus: fração n-hexano (FHDH), fração de clorofórmio (FHDC) e fração de etanol (FHDHA), depois submeterem da fração etanólica a cromatografia SPE $\mathrm{C}_{18}$, resultando no fracionamento de cinco subfrações etanólicas: FHDHA 1, FHDHA 2, FHDHA 3, FHDHA 4 e FHDHA 5, foram avaliadas FHDHA, FHDHA 1 e plumieride (composto já reconhecido no látex de H. drasticus em estudos passados) na exibição de atividade antidiabetes tipo II, notou-se que houve a inibição das enzimas a-amilase e a-glucosidase, resultando na retardação da absorção de glicose, essa resposta foi associada aos compostos detectados na fração lacftífera etanólica FHDHA 1: a-etil glucosídeo, ácido prototecuico, ácido 3-O-cafeoilquínico, ácido 15-desmetilplumierida, ácido 5-O-cafeoilquínico, ácido cafeíco, ácido vanílico e plumieride (Morais et al., 2020).

A amplitude de atividades biológicas demonstradas pelo o látex de $H$. drasticus reforçam sobre a importância da realização de um manejo sustentável da espécie brasileira endêmica, visto que a extração excessiva de látex em áreas de hotspot tem afetado a genética de H. drasticus (Baldauf et al., 2013). 


\subsubsection{Cryptostegia spp.}

O gênero Cryptostegia compreende a duas espécies arbustivas, a C. madagascariensis (Bojer) e C. grandiflora (R. Br.) conhecidas popularmente como: unha-de-bruxa, unha-do-cão, trepadeira, videira de borracha, allamanda roxa, dentre outros nomes, ambas são originárias da Ilha de Madagascar, mas encontram-se distribuídas por diferentes continentes (Klackenberg, 2001; Flora Brasil, 2020).

No Brasil, ambas as espécies são consideradas como plantas exóticas invasoras biológicas, pois afetam o funcionamento de ecossistemas, por não terem predadores naturais, possuem uma vantagem a mais sobre espécies nativas (Barbosa, et al., 2019; Gonçalves et al., 2015; Mantoani et al., 2013). Adicionalmente, tornam-se espécies competitivas na busca por água, luz, nutrientes, dentre outros recursos, ocasionando desequilíbrios no fluxo da cadeia alimentar, devido a competição e predação de recursos (Medeiros et al., 2018). A alternativa mais apropriada para lidar com a invasão biológica, seria o estabelecimento de planos de manejos de espécies exóticas invasoras no combate ao processo de invasão biológica (Santos \& Fabricante, 2019). Em casos de difícil erradicação de espécies invasoras é apropriado que seja feita a busca pela utilização dessas espécies, como a síntese de inseticidas e repelente, no caso de espécies que tenham substâncias tóxicas, dentre outras opções (Morais \& Marinho-Prado, 2016). Apesar do gênero Cryptostegia possuir toxicidade, é viável o uso de suas folhas, raízes, flores, sementes e látex, pois essas partes podem apresentar a presença de princípios ativos com funções diversificados, tais como: antitumorais, anti-inflamatórios, anticorrosivo, inseticidas, dentre outras opções (Morais et al., 2021).

\subsubsection{Cryptostegia grandiflora (R. Br.)}

É sabido que C. grandiflora apresenta alta toxicidade para mamíferos, criadores na Etiópia relataram o óbito de animais (ovelhas, gado, bode e camelo) após a ingestão das folhas da espécie (Abule et al., 2005). Tem-se que C. grandiflora e C. madagascariensis apresentam em seus tecidos vegetais glicosídeos cardíacos, esses compostos influenciam o sistema cardiovascular por meio da inibição do mecanismo de ação da bomba sódio-potássio, $\mathrm{Na}^{+} / \mathrm{K}^{+}$-ATPase (Ramos et al., 2009; Konno, 2011; Aubry, 2012; Sanduja et al., 1984). Em decorrência disso, espécies que apresentam glicosídeos cardíacos são ditas como plantas cardioativas, e podem ser utilizadas nos tratamentos de insuficiência cardíaca e taquicardia (Akinomoladun et al., 2014).

Em estudos com extratos etanólicos das folhas secas de $C$. grandiflora isolaram os seguintes glicosídeos cardíacos: oleandrigenina $\quad 3$ - $O$ - $\beta$-glucopiranosil-( $1 \rightarrow 4)-\beta$-cymaropyranosyl-( $1 \rightarrow 4)-\beta$-digitoxopyranoside; $\quad$ oleandrigenina $\quad 3-O$ - $\beta$ glucopiranosil-( $1 \rightarrow 4)-\alpha$-ramnopiranosídeo; $\quad 16$-propionilgitoxigenina $\quad 3$ - $O$ - $\beta$-glucopiranosil-( $1 \rightarrow 4$ )- $\alpha$-ramnopiranosídeo; Oleandrigenina $\quad 3$ - $O$ - $\beta$-glucopiranosil- $(1 \rightarrow 6)-\beta$-glucopiranosil-( $1 \rightarrow 4)-\beta$-cimaropiranosil-( $1 \rightarrow 4)-\beta$-digitoxopiranosídeo; cardenolídeos subalpinosídeo e 16- $O$-acetil-digitalinum verum (Kamel et al., 2001). Os compostos oleandrigenina 3- $O$ - $\beta$ -

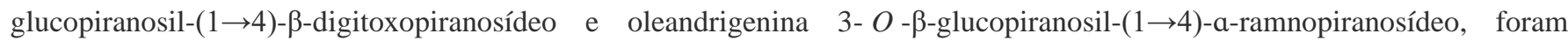
isolados das culturas de brotos de C. grandiflora (El-Mawla, 2010). Glicosídeos cardíacos, são compostos derivados de esteróides, esses por sua vez são derivados de triterpenos tetracíclicos. Sabe-se que os constituintes do grupo dos triterpenos podem ter ação antimicrobiana, tanto que ao estudarem a atividade bactericida do extrato etanólico das folhas de $C$. grandiflora, observaram a inibição das cepas Staphylococcus aureus, Klebsiella pneumoniae e Pseudomonas aeruginosa, visto que nas amostras continham a presença triterpenos (Rivela et al., 2015). Assim como, em cascas de C. grandiflora, as quais exibiram atividade contra E. coli e C. albicans, (Singh et al., 2011).

O extrato alcoólico e sua fração de petróleo, obtidos das flores e sementes de Cryptostegia grandiflora (R. Br.) exibiram atividade antimicrobiana a frente de Bacillus subtilis Cohn (1872), Aspergillus fumigatus Fresensius (1863) e Pseudomonas aeruginosa, enquanto que o extrato alcóolico das sementes demonstrou atividade contra células do carcinoma 
ascítico de Ehrlich (EAC), foram encontrados glicosídeos, carboidratos, triterpenos dentre outros metabólitos, mas não houve identificação de constituintes (Zalabani et al., 2003). Na literatura, o extrato metanólico de folhas de C. grandiflora exibiu propriedades analgésicas, análises fitoquímicas identificaram a presença de alcalóides, glicosídeos, flavonóides, esteroides, saponinas, taninos e compostos fenóis, entretanto não houve isolamento de constituintes, logo os autores propuseram que o potencial analgésico foi exercido por um fitoconstituite ou sinergismo (Hanumanthappa et al., 2012). Enquanto que, ao estudarem os efeitos do extrato etanólico de folhas de C. grandiflora, observou-se atividade anti-inflamatória em resposta ao uso de 12-O-tetradecanoil-forbol-13-acetato (TPA) em camundongos, notou-se redução de óxido nítrico e na produção de prostaglandina $\mathrm{E}_{2}$, e houve eliminação de radicais livres, com efeito dependente da concentração (Castro; Ocampo \& Franco, 2014).

Propriedades antioxidantes e anti-proliferativas, foram detectadas no extrato metanólico das folhas de C. grandiflora ao combater as células de adenocarcinoma colorretal (Caco-2), tais atividades foram associadas com a ação de enzimas antioxidantes hepáticas; catalase, peroxidase e superóxido dismutase, e com a presença de compostos fenólicos, a análise feito no HPLC identificou: dopamina, resorcionol e os flavonoides: definidina, malvidina, os autores propuseram isolamento dos compostos (Santhosoh et al., 2014).

A corrosão ocasiona prejuízos ao setor industrial, pois reduz a vida útil de produtos, em decorrência disso a busca por agentes anticorrosivos tem sido realizada. Ao ser avaliado o extrato metanólico de folhas de C. grandiflora no aço carbono em $1 \mathrm{M} \mathrm{H}_{2} \mathrm{SO}_{4}$ (ácido sulfúrico) observou-se que houve diminuição da taxa de corrosão, uma análise feita em HPLC exibiu em maiores concentrações a presença de miricetina $(3582,22 \mu \mathrm{g} / \mathrm{g})$, ácido gentísico $(77,23 \mu \mathrm{g} / \mathrm{g})$ e quercetina $(75,55 \mu \mathrm{g} / \mathrm{g})$ (Prabakaran et al., 2016).

O látex de C. grandiflora tem sido amplamente estudado, em especial no que diz respeito aos metabólitos primários, pois as proteínas existentes no látex podem apresentar propriedades promissoras para fins farmacológicos. Ao testarem o efeito antioxidante das proteínas lactíferas de $C$. grandiflora (CgLP) observou-se boa atividade peroxidase e potencial antioxidante (Freitas et al., 2010). Ao usarem uma proteína cisteína purificada do látex de C. grandiflora (Cg24-I) notou-se atividade proteolítica inibitória no crescimento de micélios na germinação de esporos de Fusarium solani (Mart.) Sacc. (1881), fungo fitopatogênico (Ramos et al., 2014). Em complemento, proteínas cisteínas peptidases se mostraram ativas contra Colleotrotricum gloesporiodes (Freitas et al., 2015).

Peptidases do látex de C. grandiflora apresentaram-se como alternativa para tratamento depilatório, apesar de ser considerada menos efetivas do que as presentes em Calotropis procera (Lopéz et al., 2017). Outra opção para o uso de peptidases da planta seria o emprego na síntese de produtos alimentícios hipoalergênicos, visto que atuaram como agente hidrolisante de proteínas no leite de vaca, resultando em significativamente como antigenicidade, na amostra testada foi encontrada a ß-lactoglobulina (Oliveira et al., 2019).

Frações de proteínas proteolíticas de $C$. grandiflora apresentaram ação similar à da enzima plasmina que é encontrada no sangue, ao demostrarem atividade fibrinogenolítica, sendo capazes de diminuírem o processo de coagulação (Viana et al., 2013). Ao avaliarem os efeitos edematogênicos, obtiveram que uma proteína solúvel isolada do látex de C. grandiflora (CgLP) apresentou atividade inflamatória por meio da migração de neutrófilos (Albuquerque et al., 2009).

A composição do látex de C. grandiflora exibi proteínas peptidases de cisteína que podem atuar como agentes protetivos (Ramos et al., 2014). Adicionalmente, o látex da espécie detém polifenóis, triglicerídios e hidrocarbonetos (cis-1,4poliispreno) (Augustus et al., 2000). Sabe-se que a presença de constituintes tóxicos no látex está vinculada ao sistema de defesa do vegetal contra patógenos ou predadores (Konno, 2011). Deste modo, esses compostos tóxicos podem ser utilizados como agentes inseticidas ou larvicidas. Ao estudarem a ação larvicida de proteínas do látex de C. grandiflora, contra larvas de Aedes aegypti L., avaliou-se que as proteínas exibiram atividade de toxicidade nas larvas (Ramos et al., 2009). Há evidências 
que o látex de C. grandiflora exerceu atividade ovicida contra Callosobruchus maculatus (Fabricius, 1775) e Zabrotis subfasciatus, (Boheman, 1833), a ação ocorreu por sinergismo de proteínas do látex, borracha e outros metabólitos (Ramos et al., 2011). O efeito moluscicida também foi relatado, pois o látex pôde atuar no controle parasitário de Biomphalaria alexandrina (Ehrenberg, 1831) e Biomaphalaria galabrata (Say, 1818), esse último molusco é o hospedeiro de Schistoma mansoni (Sambon, 1907), invertebrado causador da doença esquistossomo (Kamelia et al., 2011).

\subsubsection{Cryptostegia madagascariensis (Bojer)}

Assim como C. grandiflora, C. madagascariensis é uma espécie promissora para pesquisas cientificas, visto que apresenta diferentes glicosídeos cardíacos, dentre outros metabólitos. Tem-se que a presença de cadernólidos no látex, na casca de caules e raízes são tóxicas, por essas características C. madagascariensis são usadas em Madagascar para a prática de mortes criminosas (Aubry, 2012). Apesar da toxicidade, a borracha vegetal no látex de C. madagascariensis tem apreciação na Índia e Madagascar, enquanto as fibras serviam para elaboração de redes de pesca (Klackenberg, 2001).

Análises cromatográficas com extratos etanólicos oriundos das folhas e ramos de C. madagascariensis revelaram os seguintes cadernólidos: Oleandrigenina, 16-anidrogitoxigenina, Digitoxigenina, 16-anidrogitoxigenina-3-rhamnosídeo, 16propionilgitoxigenina-3- rhamnosídeo e 14,16-Dianidrogitoxigenina-3-rhamnosídeo (Sanduja et al., 1984). Um estudo recente com isolados de cardenólidos, dentre eles digitoxigenina, demonstrou que houve efeito antiviral ao testarem os cardenólidos em células epiteliais testiculares de suínos e células de adenocarcinoma de cólon humano (HCT-8), contra um tipo de coronavírus humano (HCoV-OC43), obteve-se que os cardenólidos influenciaram negativamente a sinalização de proteínas Janus quinase 1 (JAK 1), essas são responsáveis por sinalizarem outras células para a indução de inflamação, os autores destacaram que essa atividade foi independente do funcionamento de $\mathrm{Na}^{+} / \mathrm{K}^{+}$-ATPase e que novos estudos usando cardenólidos na perspectiva antiviral serão conduzidos (Yang et al., 2020).

Ao avaliarem o extrato etanólico de folhas de C. madagascariensis frente a Artemia salina, observou-se ocorrência de toxicidade e a presença de fenóis e taninos flobafênicos (Barbosa et al., 2017). Ao mesmo tempo que, extratos aquosos de diferentes partes: flores, frutos, folhas da planta, flores e folhas presentes da serapilheira, e o extrato bruto de $C$. madagascariensis exerceram atividade alelopática, ao ocasionarem redução na germinação de sementes e crescimento de Lactuca sativa L., alface, a autora relata que o extrato das flores de serapilheira foi o mais significativo na redução do índice de velocidade (IVG) e no crescimento inicial, constatou-se que esse efeito ocorreu devido a presença dos metabólitos secundários existentes, dentre os quais foram identificados: ácido cítrico, quercentina-3-O-gal-1,6-rhm e ácido caféico hexose (Araújo, 2017).

Ao serem testados extratos aquosos de folhas secas, folhas frescas e látex de C. madagascariensis sobre sementes de L. sativa L., Leucaena leucocephala (Lam.) de Wit, leucena, Cenchrus echinatus L. capim-carrapicho, Anadenanthera colubrina (Vell.) Brenan, angico, e Pithecellobium dulce (Roxb.) Benth, mata-fome, notou-se que o látex exerceu maior inibição no comprimento das plântulas em L. sativa, L. leucocephala e C. echinatus, no entanto ao observar os dados do IVG e a germinação das espécies percebe-se que sua ação foi inferior aos extratos das folhas, dentre os tratamentos, L. leucocephala e P. dulce demonstraram maior resistência aos efeitos de alelopatia (Pinheiro et al., 2020).

Ao avaliarem o efeito do látex como potencial antioxidante e atividade antiacetilcolinesterasica de frações etanólicas, hexanicas e do material precipitado do látex de C. madagascariensis, correlacionando ao turno que o látex coletado (manhã e tarde) e ao fator sazonal (estação chuvosa e seca), sendo realizada uma prospecção fitoquímica qualitativa, análise em HPLC e cromatografia acoplada a espectrometria de massas (CG-MS), obteve-se que as frações etanólicas exibiram melhores resultados para as atividades antioxidante e antiacetilcolinesterasica, levando em consideração turno e estação, pois os efeitos antioxidantes foram mais significativos pela tarde, e no período seco, entretanto a atividade de inibição da enzima 
acetilcolinesterase foi mais efetiva na parte da tarde e na estação seca, encontraram: fenóis, taninos, flavononóis, flavonas, flanonois, xantonas, alcalóides, esteroides e triterpenos existentes nas amostras lactíferas, a análise do HPLC detectou os compostos ácido gálico e rutina, à medida que em CG-MS houve a revelação de trinta componentes, dentre os majoritários estavam: 3-hidroxihexadecanoato de metila, 3-hidroxioctadecanoato de metila e ácido 9-octadecenóico (Pinheiro et al., 2020). Ambos os constituintes identificados no HPLC exibem atividade antioxidante, sendo que o ácido gálico é um polímero hidrossolúvel utilizado como referência em estudos que objetivam detectar a quantificação de fenóis existentes em uma amostra (Morais \& Vieira, 2018).

\subsubsection{Allamanda blanchetti A. DC.}

O gênero Allamanda L. é composto por treze espécies (Flora Brasil, 2020). Dentre as representantes, destaca-se a Allamanda blanchetti A. DC. que tem como sinônimo Allamanda violacea Gardner, sendo conhecida popularmente como "Sete-Patacas-Roxa", é uma espécie nativa no Brasil, com ocorrência principalmente na região da Caatinga (Flora Brasil, 2020).

Na medicina popular, as folhas de A. blanchetti são usadas para tratamento de problemas no coração e pressão alta (Almeida et al., 2005). Em estudos laboratoriais, os extratos metanólicos das folhas de A. blanchetti efetuaram atividade antioxidante, pelo método da eliminação de radicais livres, assim como toxicidade frente a Artemia salina, e ação trombolítica moderada, os extratos desencadearam proteção às hemácias no processo de hemólise, adicionalmente potencial antibacteriano contra Staphylococcus aeurs (Sharmin et al., 2013). A atividade antibacteriana também foi notada ao testarem extratos aquosos sintetizados da planta inteira, frente a Acidovorax citrulli (Schaad et al. 1978) Schaad et al. 2009, Pectobacteruim carotovorum subsp. carotocorum (Jones, 1901) Hauben et al. 1999, e Xanthomonas campestres pv. campestres (Silva et al., 2016).

Houve detecção de atividade antifúngica por um extrato alcoólico das folhas de A. blanchetti, ao servir como elicitor, aumentando a resistência da cana-de-açúcar em combate ao fungo patogênico ocasionador da doença carvão, Sporisoruim scitamineum (Syd.) M. Piepenbr., M. Stoll e Oberw., 2002, (Oliveira, 2012). Ao passo que, extratos de clorofórmio, metanol e éter de petróleo, feitos com as folhas de A. blanchetti mostraram-se ativos na inibição do crescimento micelial de fungo Colleototrichum gloeosporioides, essa ação teve interferência dos constituintes químicos, identificou-se a plumericina como composto majoritário, estavam presentes sitosterol, actinidiolida, tetrametil hexadecenol, campesterol, estigmasterol, dentre outros que agiram em sinergismo (Haron et al., 2013).

Pesquisas conduzidas com extratos etanólicos de A. blanchetti também têm demonstrado propriedades antimicrobianas. Por exemplo, extratos etanólicos dos frutos de A. blanchetti exibiram atividade antifúngica contra $C$. gloeosporioides e exerceram redução de antracnose em Carica papaya L. mamão, esse fato foi associado a ação da enzima peroxidase (Demartelare et al., 2015). Em outro estudo, extratos etanólicos das folhas de A. blanchetti inibiram a germinação de esporos do fungo Alternaria brassicicola (Schwein.) Wiltshire, 1947 (Barros et al., 2015). À medida que extratos etanólicos das folhas e talos de $A$. blanchetti, submetidos a cromatografias em coluna, geraram frações de acetato de etila que exibiram a presença dos compostos: estigmasterol, B-sitosterol, nonadecan-1-ol, plumericina, ácido oleánólico, ácido ursólico, B-amirina, a-amirina e lupeol, obteve-se que as frações de acetato de etila desempenharam resultados significativos nas atividades: antioxidante, antibacteriana frente a Escherichia coli e ação fotoprotetora (Silva et al., 2017).

Ao estudarem a composição química dos extratos brutos etanólicos feitos de raízes, caules, folhas e frutos de $A$. blanchetti foram identificados os compostos: terpenos, esteróides, plumericina, estigmasterol, B-sistosterol, ácido ursólico e grupos fenólicos, em todas as partes utilizadas da planta, enquanto que nas folhas e caules estavam presentes: kaempferol, plumierídeo, isoquercitrina, quercetina-3-O-glicosídeo e canferol-3-O-ß-namnosídeo, sendo que os constituintes quercitrina, quercetina, 5,7,4' tri-hidroxi-isoflavona foram isolados apenas das folhas, a rutina das flores, e os constituintes: iridóide 
plumericina, ácido p-hidroxi-cinâmico, eudesmina e ácido ursólico das raízes, dos testes biológicos realizados com os extratos observou-se que todos apresentaram atividade antibacteriana frente a Selenomas noxia Moore et al. 1987, e Fusobacterium nucleatum subsp. nucleatum (Knorr, 1922) Dzink et al. 1990, tanto quanto houve atividade anti-parasitária contra Menopon galliane L., piolhos, e potencial antileucêmico em células endoteliais, endoteliais do cordão umbilical e leucêmicas (Navarro, 2005).

Assim como os extratos biológicos de A. blanchetti exibem atividades antimicrobianas, é possível tornar viável a utilização de microrganismos presentes nos tecidos vegetais. Visto que, os fungos endófitos Phomopsis Sacc \& Roum e Alternaria Ness, isolados dos tecidos de A. blanchetti exibiram citotoxicidade e atividade antitumoral a frente da linha celular de câncer de mama (MCF-7), por meio da inibição do crescimento das células cancerígenas (Pednekar et al., 2019).

Em relação as propriedades biológicas do látex de A. blanchetti, tem-se que o conhecimento etnofarmacologico de comunidades no Cariri Paraibano, no Brasil, usa o látex diluído em água e ingerido após as refeições para atuar como laxante, emético e catártico (Agra et al., 2007), problemas cardíacos e hipertensão (Albuquerque et al., 2007).

\section{Considerações Finais}

Diante da obtenção dos dados, fica evidente que o látex de espécies da família Apocynaceae apresenta propriedades biológicas promissoras. Pois, a maioria dos látex das plantas exibiram atividades: antibacteriana, antifúngica, anti-inflamatória, antioxidante, antitumoral e larvicida. Deste modo, torna-se necessário a concretização de pesquisas que envolvam a identificação, isolamento e aplicação de compostos presentes nos fluidos lactíferos, visto que tais constituintes podem agregar valor a síntese de fármacos em prol da saúde pública, incentivar pesquisas de prospecção vegetal que gerem menos impactos na extração de recursos naturais, dentre outras perspectivas futuras.

Estudos futuros poderão investigar a fundo a constituição química dos látex, com enfoque na busca da síntese de drogas terapêuticas ou investigações para serem integradas ao controle biológico, por meio da formulação de inseticidas, visando a obtenção de um produto eficaz e menos agressivo que os sintéticos.

\section{Agradecimentos}

Agradecemos à UECE e CAPES pela assistência e contribuição para o desenvolvimento e elaboração desse estudo.

\section{Referências}

Abarca, L. F. S., Klinkhamer, P. G. L., \& Choi, Y. H. C. (2019). Plant látex, from ecological interests to bioactive chemical resources. Planta Medica. 85 (11), 856-868. https://dx.doi.org/10.1055/a-0923-8215

Abule, E., Snyman, H. A., \& Smit, G. N. (2005). Comparisons of pastoralists perceptions about rangeland resource utilisation in the Middle Awash Valley of Ethiopia. Journal of Environmental Management, 75(1), 21-35. https://doi.org/10.1016/j.jenvman.2004.11.003

Agra, M. F., Baracho, G. S., Nurit, K., Basílio, I. J. L. D., \& Coelho, V. P. M. (2007). Medicinal and poisonous diversity of the flora of "Cariri Paraibano", Brazil. Journal of Ethnopharmacology, 111(2), 383-395. http://dx.doi.org/10.1016/j.jep.2006.12.007

Akinmoladun, A. C., Olaleye, M. T., \& Farombi, E. O. (2014). 13 - Cardiotoxicity and Cardioprotective Effects of African Medicinal Plants. Toxicological Survey of African Medicinal Plants,1(1), 395-421. https://doi.org/10.1016/B978-0-12-800018-2.00013-3

Albuquerque, T. M., Alencar, N. M. N., Figueiredo, J. G., Figueiredo, I. S. T., Teixeira, C. M., Bitencourt, F. S., Secco, D. D., Araújo, E. S., Leão, C. A. A. M., \& Ramos, M. V. (2009). Vascular permeability, neutrophil migration and edematogenic effects induced by the latex of Cryptostegia grandiflora Toxicon, 53(1), 15-23. https://doi.org/10.1016/j.toxicon.2008.10.009

Albuquerque, U. P., Medeiros, P. M., Almeida, A L. S., Monteiro, J. M., Neto, E. M. F. L., Melo, J. G., \& Santos, J. P. (2007). Medicinal plants of the caatinga (semi-arid) vegetation of NE Brazil: a quantitative approach. Journal of Ethnopharmacology, 114(1), 325-354. http://dx.doi.org/10.1016/j.jep.2007.08.017 
Almeida, C. F. C. B. R., Lima e Silva, T. C., Amorim, E. L. C., Maia, M. B. S., \& Albuquerque, U. P. (2005). Life strategy and chemical composition as predictors of the selection of medicinal plants from the caatinga (Northeast Brazil). Journal of Arid Environments, 62(1), 127-142. https://doi.org/10.1016/j.jaridenv.2004.09.020

Almeida, LM; Magno, LN; Pereira, AC; Guidelli, ÉJ; Filho, OB; Kinoshita, A \& Gonçalves (2019). Toxicity of silver nanoparticles released by Hancornia speciosa (mangabeira) biomembrane. Spectrochimica Acta. Part A: Molecular and Biomolecular Spectroscopy, 210(1), 329-334. https://doi.org/10.1016/j.saa.2018.11.050

Al-Qahtani, M. A. M., Farah, M. A., Abou-Tarboush, F. M., Al-Anazi, K. M; Al-Harbi, N. O., Ali, M. A. \& Hailan, W. A. Q. (2020). Anticancer effects of Calotropis procera latex extract in mcf-7 breast câncer cells. Pharmacognosy Magazine, 16(71), 550-556. http://dx.doi.org /10.4103/pm.pm_156_20 Apocynaceae in Flora do Brasil (2020) http://floradobrasil.jbrj.gov.br/reflora/floradobrasil/FB48/_Acesso 10/04/2021

Araújo, H. T. N. (2017). Potencial alelopático e identificação de compostos de Cryptostegia madagascariensis Bojer ex Decne (Dissertação de mestrado). Programa de Pós-Graduação em Agronomia/Fitotecnia. Universidade Federal do Ceará, Fortaleza, Ceará, Brasil.

Arruda, A. S., Faria, R. Q., Peixoto, N., Moreira, A. S. F. P., Floriano, J. F., Graeff, C. F. O., Gonçalves, P. J., \& Almeida, L. M. (2016). Avaliação da produção de látex em mangabeiras do Cerrado goiano. Ciência Florestal, 26(3), 939-948. https://doi.org/10.5902/1980509824222

Assumpção, C. F., Bachiega, P., Morzelle, M. C., Nelson, D. L., Ndiaye, E. A., Rios, A. de O., \& Souza, É. C. (2014). Characterization, antioxidant potential and cytotoxic study of mangaba fruits. Ciência Rural, 44(7), 1297-1303. https://doi.org/10.1590/0103-8478cr20130855

Aubry, P. (2012). Intoxications par les plantes toxiques dans les zones tropicales et inter tropicales. Medecine Tropicale,Diplôme de Médecine Tropicale des Pays de I'Océan Indien, 1(1),1-10. http://medecinetropicale.free.fr/cours/intoxplante.pdf

Augustus, G. D. P. S., Jayabalan, M., \& Seiler, G. J. (2000). Cryptostegia grandiflora - a potential multi-use crop. Industrial Crops and Products, 11(1), 5962. https://doi.org/10.1016/S0926-6690(99)00036-9

Baldauf, C., Ciampi-Guillardi, M., Santos, F. A. M., Souza, A. P., \& Sebbenn, A. M. (2013). Tapping latex and alleles? The impacts of latex and bark harvesting on the genetic diversity of Himatanthus drasticus (Apocynaceae). Forest Ecology and Management, 310(1), 434-441. http://dx.doi.org/10.1016/j.foreco.2013.08.049

Barbosa, E. M., Bonila, O. H., Lucena, E. M. P., Araújo, L. M. A., \& Oliveira, S. R. S. (2019). Estrutura de um fragmento de Caatinga infestado por Cryptostegia madagascariensis Bojer ex Decne. Revista Brasileira de Geografia Física, 12(5), 1952-1966. https://doi.org/10.26848/rbgf.v12.5.p1952-1966

Barbosa, E. M., Tavares, F. J. C., \& Bonilla, O. H. (2017). Testes fitoquímicos e toxicológico com Cryptostegia Madagascariensis Bojer Ex Decne (Periplocoideae, Apocynaceae). Encontro Internacional De Jovens Investigadores Edição Brasil. Fortaleza. http://Www.Editorarealize.Com.Br/Artigo/Visualizar/50186

Barros, J. S. G., Gomes, E. C. S., \& Cavalcante, L. S. (2015). Efeito de extratos de Allamanda blanchetti no controle de Alternaria brassicicola em mudas de couve-manteiga. Revista Caatinga, 28(3), 36-46. http://dx.doi.org/10.1590/1983-21252015v28n304rc

Base de dados de espécies exóticas invasoras do Brasil, Instituto Hórus de Desenvolvimento e Conservação Ambiental, Florianópolis - SC. http://bd.institutohorus.org.br/www Acesso 30/03/2021.

Bastos, K. X., Dias, C. N., Nascimento, Y. M., da Silva, M. S., Langassner, S. M. Z., Wessjohann, L. A., \& Tavares, J. F. (2017). Identification of phenolic compounds from Hancornia speciosa (Apocynaceae) leaves by UHPLC Orbitrap-HRMS. Molecules, 22(1),2-11. http://dx.doi.org/10.3390/molecules22010143.

Bonete, J. M., Silva, G. D. S., Guidelli, É. J., Gonçalves, P. J., Almeida, L. M., Baffa, O., \& Kinoshita, A. (2020). Tissue reaction and anti-biofilm action of new biomaterial composed of latex from Hancornia speciosa Gomes and silver nanoparticles. Anais da Academia Brasileira de Ciências, 92(4), 1-14. e20191584 DOI 10.1590/0001-3765202020191584

Brito, A. S., Coutinho, H. D. M., Barros, A. R. C., Rodrigues, F. F. G., \& Costa, J. G. M. (2010). Prospecção fitoquímica e avaliação da atividade antibacteriana e toxicidade do látex de Calotropis procera (Asclepidaceae). Cadernos de Cultura e Ciência, 2 (2), 31-39. http://periodicos.urca.br/ojs/index.php/cadernos/article/view/236/145

Castro, J. P., Ocampo, Y. C., \& Franco, L. A. (2014). In vivo and in vitro anti-inflammatory activity of Cryptostegia grandiflora Roxb. ex R. Br. leaves. Biological Research, 47(1), 1-8. https://doi.org/10.1186/0717-6287-47-32

Castro, M. M., \& Machado, S. R. (2006). Células e tecidos secretores. In: APPEZZATO-DA-GLÓRIA, B. \& CARMELLO-GUERREIRO, S. M. Anatomia vegetal (pp.179-188): Editora UFV.

Cavalcante, G. S. (2015). Composição química e avaliação in vitro do extrato acetato de etila do látex de Calotropis procera (Ait) (Apocynaceae) sobre Haemonchus contortus (Dissertação de mestrado). Programa de Pós-Graduação em Ciências Veterinárias da Faculdade de Veterinária. Universidade Estadual do Ceará, Fortaleza, Ceará, Brasil

Cavalcante, G. S., Morais, S. M., André, W. P. P., Araújo-Filho, J. V., Muniz, C. R., Rocha, L. O., Ribeiro, W. L. C., Rodrigues, A. L. M., Oliveira, L. M. B., Bevilaqua, C. M. L., \& Ramos, M. V. (2020). Chemical constituents of Calotropis procera latex and ultrastructural effects on Haemonchus contortus. Brazilian Journal of Veterinary Parasitology, 29(2),1-12. https://doi.org/10.1590/s1984-29612020045

Choedon, T., Mathan, G., Arya, S., Kumar, V. L., \& Kumar, V. (2006). Anticancer and cytotoxic properties of the latex of Calotropis procera in a transgenic mouse modelo f hepatocellular carcinoma. World Journal of Gastroenterology, 12(16), 2517-2522. http://dx.doi.org /10.3748/wjg.v12.i16.2517

Chundattu, S. J., Agrawal, V. K., \& Ganesh, N. (2016). Phytochemical investigation of Calotropis procera. Arabian Journal of Chemistry, 9(1), 5230-5234. https://doi.org/10.1016/j.arabjc.2011.03.011 
Colares, A. V., Cordeiro, L. N., Costa, J. G. M., Cardoso, A. H. \& Campos, A. R. (2008). Efeito gastroprotetor do látex de Himatanthus drasticus (Mart.) Plumel (janaguba). Infarma Ciências Farnacêticas, 20(11), 34-36. http://revistas.cff.org.br/?journal=infarma\&page=article \&op=view\&path $\% 5 \mathrm{~B} \% 5 \mathrm{D}=182 \&$ path $\% 5 \mathrm{~B} \% 5 \mathrm{D}=172$

Coutinho, T. S. (2017). Apocynoideae Burnett (Apocynaceae) no Nordeste Oriental do Brasil (Dissertação de mestrado). Programa de Pós-Graduação em Biologia Vegetal-PPCBV. Universidade Federal de Pernambuco, Recife, Pernambuco, Brasil.

Cunha, A. L., Moura, K. S., Barbosa, J. C., \& Santos, A. F. (2016). Os metabólitos secundários e sua importância para o organismo. Diversitas Journal. 1(2), 175-191. doi.org/10.17648/diversitas-journal-v1i2.332

D’Abadia, P. L., Bailão, E. F. L. C., Júnior, R. S. L., Oliveira, M. G., Silva, V. B., Oliveira, L. A. R., Conceição, E. C., Melo-Reis, P. R., Borges, L. L., Gonçalves, P. J., \& Almeida, L. M. (2020). Hancornia speciosa serum fraction latex stimulates the angiogenesis and xtracelular matrix remodeling processes. Anais da Academia Brasileira de Ciências, 92(2),1678-2690. 10.1590/0001-3765202020190107

D’Abadia, P. L., Bailão, E. F. L. C., Oliveira, L. A. R., Conceição, E. C., Borges, L. L., \& Almeida, L. M. (2018). Caracterização química e avaliação dos potenciais antioxidante e antibacteriano da fração aquosa do látex de mangabeira. V Congresso de Ensino, Pesquisa e Extensões da UEG, 5(1), 1-10. https://www.anais.ueg.br/index.php/cepe/article/view/12657

De Almeida, S. C. X., da Silva, Â. C. F., Sousa, N. R. T., Amorim, I. H. F., Leite, B. G., Neves, K. R. T., Costa, J. G. M., Felipe, C. F. B. \& de Barros Viana, G. S. (2019). Antinociceptive and anti-inflammatory activities of a triterpene-rich fraction from Himatanthus drasticus. Brazilian Journal of Medical and Biological Research, 52(5), 1-12. doi.org/10.1590/1414-431X20197798

Demartelaere, A. C. F., Guimarães, G. H. C., Silva, J. A., Luna, R. G., \& Nascimento, L. C. (2015). Extratos vegetais no controle da antracnose e na conservação da qualidade em frutos de mamoeiro. Revista Brasileira de Plantas Medicinais, 17(4),1041-1048. 10.1590/1983-084x/14_147

El-Mawla, A. M. A. A. (2010). Cardiac glycosides from shoot cultures of Cryptostegia grandiflora. Pharmacognosy Research, 2(1), 15-18. 10.4103/09748490.60583

Felipetti, F. A., Bereta, R. M., Piedade, S. M. S., \& Novaes, P. D. (2019). Administrações Orais do Látex da Hancornia speciosa Gomes não aumentam a neoformação óssea. Revista Brasileira de Ortopedia, 54(6), 692-696. https://doi.org/10.1055/s-0039-1697019

França, W. C. S. C., Souza, A. C. R. L. A., Cordeiro, J. A., \& Cury, P. M. (2011). Análise da ação da Himatnathus drasticus na progressão do câncer de pulmão induzido por uretana em camundongos. Einstein, 9(3), 350-353. 10.1590/s1679-45082011ao2013

Freitas, A. P. F., Bitencourt, F. S., Brito, G. A. C., Alencar, N. M. N., Ribeiro, R. A., Lima-Júnior, R. C. P., Ramos, M. V., \& Vale, M. L. (2012). Protein fraction of Calotropis procera latex protects against 5-fluorouracil-induced oral mucositis associated with downregulation of pivotal pro-inflammatory mediators. Naunyn-Schmiedeberg's Arch Pharmacol, 385(1), 981-990. 10.1007/s00210-012-0778-3

Freitas, C. D. T., Silva, M. Z. R., Moreno, F. B., Moreira, A. C. O. M., Moreira, R. A., \& Ramos, M. V. (2015). New constitutive latex osmotin-like proteins lacking antifungal activity. Plant Physiology and Biochemistry, 96(1), 45-52. 10.1016/j.plaphy.2015.07.012

Freitas, C. D. T., Souza, D. P., Araújo, E. S., Cavalheiro, M. G., Oliveira, L. S., \& Ramos, M. V. (2010). Anti-oxidative and proteolytic activities and protein profile of laticifer cells of Cryptostegia grandiflora, Plumeria rubra and Euphorbia tirucalli. Brazilian Society of Plant Physiology, 22(1), 11-22. https://doi.org/10.1590/S1677-04202010000100002

Freitas, C. D. T., Viana, C. A., Vasconcelos, I. M., Moreno, F. B. B., Lima-Filho, J. V., Oliveira, H. D., Moreira, R. A., Monteiro-Moreira, A. C. O., \& Ramos, M. V. (2016). First insights into the diversity and functional properties of chitinases of the latex of Calotropis procera. Plant Physiology and Biochemistry, 108(1), 361-371. https://doi.org/10.1016/j.plaphy.2016.07.028

Gonçalves, G. S., Andrade, L. A., Xavier, K. R. F., \& Silva, J. F. (2015). Métodos de controle de Prosopis juliflora (Sw.) DC. (Fabaceae) em áreas invadidas no semiárido do Brasil. Ciência Florestal, 25(3), 645-653. https://doi.org/10.5902/1980509819615

Halfeld-Vieira, B. A., Marinho-Prado, J. S., Morandi, M. A. B., \& Bettiol, W. (2016). Defensivos agrícolas naturais: uso e perspectivas (21a ed). Brasília, DF: Embrapa.

Hanumanthappa, S. K., Hanumanthappa, M., Venkatarangaiah, K., Krishnappa, P., \& Gupta, R. K. P. (2012). Analgesic activity of Cryptostegia grandiflora (Roxb.)R.br. leaves methanol extract using mice. Asian Pacific Journal of Tropical Disease, 2(1), 494-498. 10.1016/S2222-1808(12)60209-6

Haron, F. F., Sijam, K., Omar, D., \& Rahmani, M. (2013). Chemical composition and screening for antifungal activity of Allamanda spp. (Apocynaceae) crude extracts against Colletotrichum gloesporioides causal agent of anthracnose in papaya. Australian Journal of Basic and Applied Sciences, 7(1), 88-96. http://www.ajbasweb.com/old/ajbas/2013/January/88-96.pdf

Junior, E. C., Costa, A. C., Ferreira, K. L. C., Silva, K. M. R., Pereira, E. M., \& Araújo, E. T. H. (2018). Avaliação da ação antimicrobiana do látex de mangabeira em duas cepas de bactérias causadoras de pneumonia. Revista Prevenção de Infecção e Saúde (REPIS), 4(1),1-10. 10.26694/repis.v4i0.6991

Kamel, M. S., Assaf, M. H., Abe, Y., Ohtani, K., Kasai, R., \& Yamasaki, K. (2001). Cardiac glycosides from Cryptostegia grandiflora. Phytochemistry, 58(4), 537-547. 10.1016/s0031-9422(01)00297-7

Kamelia, A., Momeana, E. S., Hanan, B. M., \& Mossalem, S. (2011). Cryptostegia grandiflora affecting compatibility of Biomphalaria alexandrina and Biomphalaria galabrata to infection with Schistosoma mansoni with emphasis on some hematological efffects. Australian Journal of Basic and Applied Sciences, 5(12), 3357-3365. http://www.ajbasweb.com/old/ajbas/2011/December-2011/3357-3365.pdf 
Klackenberg, J. (2001). Revision of the genus Cryptostegia R. Br. (Apocynaceae, Periplocoideae). Adansonia, 23(2), 205218.https://Sciencepress.mnhn.fr/en/Periodiques/Adansonia/23/2/Revision-Du-Genre-Cryptostegia-R-Br-Apocynaceae-Periplocoideae

Koche, J. C. (2011). Fundamentos de metodologia científica. Petrópolis: Vozes. Disponível em: http://www.adm.ufrpe.br/sites/ww4.deinfo.ufrpe.br/files/Fundamentos_de_Metodologia_Cienti\%CC\%81fica.pdf

Konno, K. (2011). Plant latex and other exudates as plant defense systems: roles of various defense chemicals and proteins contained therein. Phytochemistry. 72 (13), 1510-1530. 10.1016/j.phytochem.2011.02.016

Kumar, A., Singh, N., \& Kumar, P. (2019). Purification and characterizations of anti-microbial protein from Calotropis procera. International Journal of Current Microbiology and Applied Sciences, 8(8), 1754-1761. 10.20546/ijcmas.2019.808.207

Kumar, S., Gupta, A., \& Pandey, A. K. (2013). Calotropis procera root extract has the capability to combat free radical mediated damage. International Scholarly Research Notices Pharmacology, 2013(1), 1-8. 10.1155/2013/691372

Lázaro, S.F., Fonseca, L. D., Fernandes, R. C., Tolentino, J. S., Martins, E. R., \& Duarte, E. R. (2012). Efeito do extrato aquoso do algodão de seda (Calotropis procera Aiton) sobre a eficiência reprodutiva do carrapato bovino. Revista Brasileira de Plantas Medicinais, 14 (2), 302-305. 10.1590/S151605722012000200008

Lêdo, A. S., Neto, R. D. V., Junior, J. F. S., Silva, A. V. C., Pereira, A. V., Pereira, E. B. C., Filho, M. M., \& Junqueira, N. T. V. (2015). A cultura da mangaba. Embrapa.

Lopez, A. M., Nagai, A., \& Faria, A.V. F. (2012). Botânica no inverno 2013. Instituto de Biociências da Universidade de São Paulo.

Lopéz, L. M. I., Viana, C. A., Errasti, M. E., Garro, M. L., Martegani, J. E., Mazzilli, G. A., Freitas, C. D. T., Araújo, Í. M. S., Silva, R. O. da, \& Ramos, M. V. (2017). Latex peptidases of Calotropis procera for dehairing of leather as an alternative to environmentally toxic sodium sulfide treatment. Bioprocess and Biosystems Engineering, 40(1), 1391-1398. https://doi.org/10.1007/s00449-017-1796-9

Lorenzi, H. (1997). Árvores brasileiras. Manual de identificação e cultivo de plantas arbóreas nativas do Brasil (1a ed.). Plantarum.

Lucetti, D. L., Lucetti, E. C., Bandeira, M. A. M., Veras, H. N. H., Silva, A. H., Leal, L. K. A. L., Lopes, A. A., Alves, V. C., Silva, G. S., Brito, G. A., \& Viana, G. B. (2010). Anti-inflammatory effects and possible mechanism of action of lupeol acetate isolated from Himatanthus drasticus (Mart.) Plumel. Journal of Inflammation, 7(60) 1-11. https://doi.org/10.1186/1476-9255-7-60

Luz, H. S., Santos, A. C. G., Lima, F. C. \& Machado, K. R. G. (2014). Prospecção fitoquímica de Himatanthus drasticus Plumel (Apocynaceae), da mesorregião leste maranhense. Revista Brasileira de Plantas Medicinais, 16(3), 657-662. http://dx.doi.org/10.1590/1983-084X/12_114

Machate, D. J., Alves, F. M., \& Farinaccio, M. A. (2016). Aspidosperma (Apocynaceae) no estado de Mato Grosso do Sul, Brasil. Rodriguésia, 67(4), 10111024. $10.1590 / 2175-7860201667411$

Magalhães, H. I. F., Ferreira, P. M. P., Moura, E. S., Torres, M. R., Alves, A. P. N. N., Pessoa, O. D. L., Costa-Lotufo, L. V., Moraes, M. O., \& Pessoa, C. (2010). In vitro and in vivo antiproliferative activity of Calotropis procera stem extracts. Anais da Academia Brasileira de Ciências, 82(2), 407-416. $10.1590 /$ S0001-37652010000200017

Maia-Silva, C., Silva, C. I., Hrncir, M. \& Queiroz, R. T. (2012). Guia de plantas visitadas por abelhas na Caatinga (1a ed.). Editora Fundação Brasil Cidadão.

Mantoani, M. C., Dias, J., Orsi, M. L., \& Torezan, J. M. D. (2013). Efeitos da invasão por Tradescantia Zebrina Heynh. sobre regenerantes de plantas arbóreas em um fragmento de floresta estacional semidecidual secundária em Londrina (Pr). Revista Biotemas, 26 (3), 63-70. 10.5007/2175-7925.2013v26n3p63

Marinho, D. G., Alviano, D. S., Matheus, M. E., Alviano, C. S., \& Fernandes, P. D. (2011). The latex obtained from Hancornia speciosa Gomes possesses anti-inflammatory acitivity. Journal of Ethnopharmacology, 135(2), 530-37. 10.1016/j.jep.2011.03.059

Medeiros, J. dos S. de, Mesquita, F. de O., Andrade, L. A. de, Oliveira, C. J. de, Japiassu, A., Medeiros, A. C. de, \& Maracaja, P. B. (2018). Comportamento vegetativo de Cryptostegia madagascariensis Bojer ex Decne em solos da Caatinga sob estresses abióticos. Revista Brasileira De Agrotecnologia, 8(2), 19-27. https://www.gvaa.com.br/revista/index.php/REBAGRO/article/view/6236

Medeiros, J. S., Mesquita, F. O., Andrade, L. A., Oliveira, C. J., Souza, E. M., \& Souza, J. K. C. (2018). Invasão biológica por Cryptostegia madagascariensis: uma abordagem voltada para estresses abióticos. Pesquisa e Ensino em Ciências Exatas e da Natureza, 2(1), 36-47. 10.29215/pecen.v2i1.579

Mohamed, S. E., \& Said, M. S. (2020). Effectiveness of Calotropis procera Ait. latex against late nymphal instars of Locusta migratoria L. (Orthoptera: Acrididae). Egyptian Journal of Agricultural Research, 98(2), 327-337. 10.21608/EJAR.2020.122586

Morais, F. S., Canuto, K. M., Ribeiro, P. R. V., Silva, A. B., Pessoa, O. D. L., Freitas, C. D. T., Alencar, N. M. N., Oliveira, A. C., \& Ramos, M. V. (2020). Chemical profiling of secondary metabolites from Himatanthus drasticus (Mart.) Plumel latex with inhibitory action against the enzymes $\alpha$-amylase and $\alpha$ glucosidase: In vitro and in silico assays, Journal of Ethnopharmacology, 253(1), 1-9. 10.1016/j.jep.2020.112644

Morais, L. A. S., \& Marinho-Prado, J. S. (2016). Plantas com atividade inseticida. In: Halfed-Vieira, B. A., Marinho-Prado, J. S., Nechet, K. L., Morandi, M. A. B., Bettiol, W. Defensivos agrícolas naturais uso e perspectivas (pp.542-593): Embrapa

Morais, S. M., Lopes, F. F. S., Fontenele, G. A., Silva, M. V. F., Fernandes, V. B., \& Alves, D. R. (2021). Total phenolic contente and antioxidante and anticholinesterase activities of medicinal plants from the State's Cocó Park (Fortaleza- CE, Brazil). Research, Society and Development, 10 (5), 1-12. $10.33448 /$ rsd-v10i5.14493

Morais, S. M., \& Vieira, Í. G. P. (2018). Introdução à prospecção de produtos naturais [livro eletrônico] Fortaleza, CE: EdUECE. 
Morais, S. M., Pinheiro, H. B., Rebouças Filho, J. V., Cavalcante, G. S., \& Bonilla, O. H. (2021). Gênero Cryptostegia: fitoquímica, atividades biológicas e aplicações industriais. Revista Química Nova, 15(1), 1-8.doi.org/10.21577/0100-4042.20170716

Moura, D. F. (2016). Avaliação da toxicidade e efeitos biológicos do látex de Himatanthus drasticus (Mart) PLUMEL (Dissertação de mestrado). Programa de Pós-Graduação em Saúde Humana e Meio Ambiente-PPGSHMA. Universidade Federal de Pernambuco, Recife, Pernambuco, Brasil.

Moura, D. F., Rocha, T. A., Barros, D. M., Silva, M. M., Lira, M. A. C., Souza, T. G. S., Silva, C. J. A., Júnior, F. C. A. A., Chagas, C. A., Santos, N. P. S., Souza, I. A., Araújo, R. M. Ximenes, R. M., Martins, R. D. \& Silva, M. V. (2020). Evaluation of the cytotoxicity, oral toxicity, genotoxicity, and mutagenicity of the latex extracted from Himatanthus drasticus (Mart.) Plumel (Apocynaceae). Journal of Ethnopharmacology, 253(1), 1-7. https://doi.org/10.1016/j.jep.2020.112567

Moura, D. F., Sobrinho, C. R. W., Barros, D. M., Filho, J. L. B. F., Silva, A. G., Rocha, T. A., Silva, S. T. F., Silva, M. M., Martins, R. D., \& Silva, M. V. (2019). Evaluation of antibiofilm activity of the latex extracted from Himatanthus drasticus (Mart.) Plumel (janaguba). International Journal of Advanced Research, 7(1), 446-450. http://dx.doi.org/10.21474/IJAR01/8348

Mousinho, K. C., Oliveira, C. C., Ferreira, J. R. O., Carvalho, A. A., Magalhães, H. L. F., Bezerra, D. P., Alves, A. P. N. N., Costa-Lotufo, L. V., Pessoa, C., Matos, M. P. V., Ramos, M. V., \& Moraes Filho, M. O. (2011). Antitumor effect of laticifer proteins of Himatanthus drasticus (Mart.) Plumel - Apocynaceae. Journal of Ethnopharmacology,137(1), 421-426. http://www.repositorio.ufc.br/handle/riufc/5534

Navarro, D. F. (2005). Estudo químico, biológico e farmacológico das espécies Allamanda blanchetti e Allamanda schottii Pohl para a obtenção de frações e moléculas bioativas de potencial terapêutico (Tese de doutorado). Curso de Pós-Graduação em Química. Universidade Federal de Santa Catarina, Florianópolis, Santa Catarina, Brasil.

Neves, J. S., Franchin, M., Rosalen, P. L., Omar, N. F., Dos Santos, M. A., Paschoal, J. A. R., \& Novaes, P. D. (2016). Evaluation of the osteogenic potential of Harcornia speciosa latex in rat calvaria and its phytochemical profile. Journal of Ethnopharmacology, 183(1), 151-158. http://dx.doi.org/10.1016/j.jep.2016.02.041

Oliveira, J. P. B., Candreva, A. M., Rizzo, G., Ramos, M. V., Oliveira, J. S., Oliveira, H. D., Ary, M. B., Docena, G., \& Freitas, C. D. T. (2019). Allergenicity reduction of cow's milk proteins using latex peptidases. Food Chemistry, 284(1), 245-253. https://doi.org/10.1016/j.foodchem.2019.01.123

Oliveira, L. M. S. (2012). Indução abiótica de genes de resistência em cana-de-açúcar relacionadas à defesa contra Sporisorium scitameneum (Dissertação de mestrado). Programa de Pós-Graduação em Ciências Biológicas. Universidade Federal de Pernambuco, Recife, Pernambuco, Brasil.

Pednekar, H. D., Hegde, H. V., Hurakadale, P. J., Wagawade, J. D., Bhat, K. G., \& Bogar, C. (2019). Cytotoxic activity of endophytes isolated from Allamanda blanchetii A. DC. Indian Journal of Health Sciences and Biomedical Research Kleu, 12(2), 112-116. http://dx.doi.org/10.4103/kleuhsj.kleuhsj_7_19

Pinheiro, H. B. (2020). Caracterização química e atividades biológicas do látex de Cryptostegia madasgacariensis Bojer (Apocynaceae) (Dissertação de mestrado). Programa de Pós-Graduação em Ciências Naturais-PPGCN. Universidade Estadual do Ceará, Fortaleza, Ceará, Brasil.

Prabakaran, M., Kim, S., Hemapriya, V., \& Chung, I. (2016). Evaluation of polyphenol composition and anti-corrosion properties of Cryptostegia grandiflora plant extract on mild steel in acidic médium. Journal of Industrial and Engineering Chemistry, 37(1), 47-56. https://www.cheric.org/research/tech/periodicals/doi.php?art_seq=1454603

Ramos, M. V., Araújo, E. S., Oliveira, R. S. B., Teixeira, F. M., Pereira, D. A., Cavalheiro, M. G., Souza, D. P., Oliveira, J. S., \& Freitas, C. D. T. (2011). Latex fluids are endowed with insect repellent activity not specifically related to their proteins or volatile substances. Brazilian Society of Plant Physiology. 23(1), 57-66. http://dx.doi.org/10.1590/S1677-04202011000100008

Ramos, M. V., Araújo, E. S., Oliveira, R. S. B., Teixeira, F. M., Pereira, D. A., Cavalheiro, M. G., Souza, D. P., Oliveira, J. S., \& Freitas, C. D. T. (2011). Latex fluids are endowed with insect repellent activity not specifically related to their proteins or volatile substances. Brazilian Society of Plant Physiology. 23(1), 57-66. https://doi.org/10.1590/S1677-04202011000100008

Ramos, M. V., Pereira, D A., Souza, D. P., Araújo, E. S., Freitas, C. D. T., Cavalheiro, M. G., Matos, M. P. V., \& Carvalho, A. F. U. (2009). Potential of laticifer fluids for inhibiting Aedes aegypti larval development: evidence for the involvement of proteolytic activity. Memórias do Instituto Oswaldo Cruz. 101(6), 805-812. https://doi.org/10.1590/S0074-02762009000600001

Ramos, M. V., Souza, D. P., Gomes, M. T. R., Freitas, C. D. T., Carvalho, C. P. S., Júnior, P. A. V. R., \& Salas, C. E. (2014). A phytopathogenic cysteine peptidase from latex of wild rubber vine Cryptostegia grandiflora. The Protein Journal, 33(10), 199-209. https://doi.org/10.1007/s10930-014-9551-4

Rapini, A. (2000). Sistemática: Estudos em Asclepiadoideae (Apocynaceae) da Cadeia do Espinhaço de Minas Gerais (Tese de doutorado). Instituto de Biociências da Universidade de São Paulo, São Paulo, São Paulo, Brasil.

Rapini, A. (2012). Taxonomy "under construction": advances in the systematics of Apocynaceae, with emphasis on the Brazilian Asclepiadoideae. Rodriguésia, 63(1), 75-88. http://dx.doi.org/10.1590/S2175-78602012000100007

Rebouças Filho, J. V., Pinheiro, H. B., Herrera, B. O., Lucena, E. M. P. de., Nascimento, S. F. do., \& Farias, I. B. M. (2021). Fitossociologia de dois bosques de Caatinga utilizados para extração foliar da Copernicia prunifera (Mill.) H. E. Moore e infestados por Cryptostegia madagascariensis Bojer. Revista Brasileira de Geografia Física, 14(2). https://doi.org/10.26848/rbgf.v14.2.p\%25p

Ribeiro, T. P., Sousa, T. R., Arruda, A. S., Peixoto, N., Gonçalves, P. J., \& Almeida, L. M. (2016). Evaluation of cytotoxicity and genotoxicity of Hancornia speciosa latex in Allium cepa root model. Brazilian Journal of Biology, 76(1), 245-249. https://doi.org/10.1590/1519-6984.20114

Rivera. D. E., Ocampo, Y. C., Castro, J. P., Caro, D., \& Franco, L. A. (2015). Antibacterial activity of Physalis angulata L., Merremia umbellata L., and Cryptostegia grandiflora Roxb. Ex R.Br.- medicinal plants of the Colombian Northern Coast. Oriental Pharmacy and Experimental Medicine, 15(1), 95-102. http://dx.doi.org/10.1007/s13596-014-0176-0 
Sanduja, R., Lo, W. Y. R., Euler, K. L., \& Alam, M. (1984). Cardenolides of Cryptostegia madasgascariensis. Journal of Natural Products, 47(2), 260-265. https://doi.org/10.1021/np50032a004

Santarém, E. R. (2017). Interações bióticas. In: Taiz, L. [et al] Fisiologia e desenvolvimento vegetal (pp.693-730): Artmed.

Santhosh, K. H., Manjunatha, H., Krishna, V., \& Swamy, B. E. K. (2014). Anti-proliferative and antioxidant of leaf methanol extract of Cryptostegia grandiflora R. Br. International Journal of Pharmacy and Pharmaceutical Sciences, 6(5), 156-164. https://www.researchgate.net/profile/SanthoshKondajji/publication/264004990

Santos, G. J. L., Oliveira, E. S., Pinheiro, A. D. N., da Costa, P. M., de Freitas, J. C. C., de Araújo Santos, F. G., Maia, F. M. M., de Morais, S. M., \& NunesPinheiro, D. C. S. (2018). Himatanthus drasticus (Apocynaceae) latex reduces oxidative stress and modulates $\mathrm{CD}^{+}{ }^{+} \mathrm{CD}^{+}, \mathrm{FoxP}^{+}{ }^{+}$and $\mathrm{HSP}^{-60^{+}}$expressions in Sarcoma 180-bearing mice. Journal of Ethnopharmacology, 220(1), 159-168. https://doi.org/10.1016/j.jep.2017.09.043

Santos, L. A., \& Fabricante, J. R. (2019). Impactos da exótica invasora Boerhavia difusa L. sobre a diversidade de espécies do estrato herbáceo e arbustivo autóctone de uma área ripária na Caatinga, Sergipe, Brasil. Scientia Plena,15(1), 1-14. https://doi.org/10.14808/sci.plena.2019.012401

Sharmin, T., Sarker, P. K., Islam, F., Chowdhury, S. R., Quadery, T. M., Mian, M. Y., Rahman, S. M. A., Chowdhury, Z. S., \& Ullah, M. S. (2013). Investigation of biological activities of Allamanda blanchetii, the violet Allamanda. Journal of Pharmacy Research, 6(7), 761-764. https://doi.org/10.1016/j.jopr.2013.07.010

Silva, A. M. S., Aguiar, T. P. C., Menezes, A. A. T., Beltrão, T., Romano, C. A., Silveira, A. A., \& Guissoni, A. C. P. (2018). Atividade larvicida do látex das folhas de Synadenium umbellatum Pax (Euphorbiacea) sobre Aedes aegypti (Díptera, Culicidae). Referências em Saúde da Faculdade Estácio de Sá de Goiás, 1 (1),14-19. https://revistaadmmade.estacio.br/index.php/rrsfesgo/article/view/5602

Silva, C. M. A., Costa, B. M. S., Silva, A. G., Souza, E. B., Silva, M. V., Silva, M. T. S. C., Sant'Anna, A. P., \& Menezes, L. V. L. (2016). Antimicrobial activity of several Brazilian medicinal plants against phytopathogenic bacteria. African Journal of Microbiology Research, 10(17), 578-583. http://dx.doi.org /10.5897/AJMR2014.6999

Silva, G. S. F. S. (2017). Estudo fitoquímico e biológico in vitro de Allamanda blanchetii A. DC. (Apocynaceae) (Dissertação de mestrado). Programa de PósGraduação em Recursos Naturais do Semiárido. Universidade Federal do Vale do São Francisco, Petrolina, Pernambuco, Brasil.

Silva, M. Z. R., Oliveira, J. P. B., Ramos, M. V., Farias, D. F., Sá, C. A., Ribeiro, J. A. C., Silva, A. F. B., Sousa, J. S. S., Zambelli, R. A., Silva, A. C., Furtado, G. P., Grangeiro, T. B., Vasconcelos, M. S., Silveira, S. R. \& Freitas, C. D. T. (2019). Biotechnological potential of a cysteine protease (CpCP3) from Calotropis procera latex for cheesemaking, Food Chemistry,307 (1), 1255-1274. http://dx.doi.org /10.1016/j.foodchem.2019.125574

Singh B., Sharma, R. A., Vyas, G. K., \& Sharma, P. (2011). Estimation of phytoconstituents from Cryptostegia grandiflora (Roxb.) R. Br. in vivo and in vitro. II. Antimicrobial screening. Journal of Medicinal Plants Research, 5(9), 1598-1605. http://www.academicjournals.org/JMPR

Soares, F. P., Almeida, F. S., Miranda, C. C., Carvalho, P. H. L., Romero, N. R., \& Bandeira, M. A. M. (2016). Avaliação da qualidade de amostras comerciais de leite de janaguba (Himatanthus drasticus (Mart.) Plumel) em Fortaleza - Ceará. Revista Brasileira de Plantas Medicinais, 18(2), 399-407. http://dx.doi.org/10.1590/1983-084X/15_198

Sousa, B. F., Silva, A. F. B., Lima-Filho, J. V., Agostinho, A. G., Oliveira, D. N., Alencar, N. M. N., Freitas, C. D. T., \& Ramos, M. V. (2020). Latex proteins downregulate inflammation and restores blood-coagulation homeostasis in acute Salmonella infection. Memórias do Instituto Oswaldo Cruz, 115(1), 01-12. http://dx.doi.org/10.1590/0074-02760200458

Sousa, F. Q., Andrade, L. A., \& Xavier, K. R. F. (2016). Cryptostegia madagascariensis Bojer ex Decne.: impactos sobre a regeneração natural em fragmentos de caatinga. Revista Brasileira de Ciências Agrárias, 11(1), 39-45. http://dx.doi.org/10.5039/agraria.v11i1a5357

Souza, V. C., \& Lorenzi, H. (2019). Botânica Sistemática: guia ilustrado para identificação das famílias de Fanerógamas nativas e exóticas no Brasil, baseado em APG IV (4a ed.) Jardim Botânico Plantrum.

Tavares, L. S., Ralph, M. T., Batista, J. E. C., Sales, A. C., Ferreira, L. C. A., Usman, A. U., Júnior, V. A. S., Ramos, M. V., \& Lima-Filho, J. V. (2021). Perspectives for the use of latex peptidases from Calotropis procera for control of inflammation derived from Salmonella infections. International Journal Of Biological Macromolecules, 171(1), 37-43. http://dx.doi.org/10.1016/J.Ijbiomac.2020.12.172

Torres-Rêgo, M., Furtado, A. A., Bitencourt, M. A. O., Lima, M. C. J. S., Andrade, R. C. L. C., Azevedo, E. P., Soares, T. C., Tomaz, J. C., Lopes, N. P., Silva-Júnior, A. A., Zucolotto, S. M., \& Fernandes-Pedrosa, M. F. (2016). Anti-inflammatory activity ofaqueous of extract and bioactive compounds identified from the fruits of Hancornia speciosa gomes (Apocynaceae). BMC Complementary and Alternative Medicine, 16 (275), 1-10. http://dx.doi.org/10.1186/s12906-016-1259-x

Viana, C. A., Oliveira, J. S., Freitas, C. D. T., Alencar, N. M. N., Carvalho, C. P. S., Nishi, B. C, \& Ramos, M. V. (2013). Thrombin and plasmin-like activities in the latices of Cryptostegia grandiflora and Plumeria rubra. Blood Coagulation \& Fibrinolysis, 24(4), 386-392. https://doi.org/10.1097/mbc.0b013e32835d540b

Vieira, M. F., Leite, M. S. O., Grossi, J. A. S., \& Alvarenga, E. M. (2004). Biologia reprodutiva de Cryptostegia madagascariensis Bojer ex Decne. (Periplocoideae, Apocynaceae), espécie ornamental e exótica no Brasil. Bragantia, 63(3), 325-334. http://dx.doi.org/10.1590/S0006-87052004000300002.

Wanderley, M. G. L., Shepherd, G. J., Melhem, T. S., Martins, S. E., Kirizawa, M., \& Giulietti, A. M. (2005). Flora fanerogâmica do estado de São Paulo Online (5a ed.). Instituto de Botânico.

Yang, C., Hsu, H., Chang, H., Lee, Y., \& Lee, S. (2020). Natural cardenolides suppress coronaviral replication by downregulating JAK1 via a Na ${ }^{+} \mathrm{K}^{+}$-ATPase independente proteolysis. Biochemical Pharmacology, 180(1), 114-122. https://doi.org/10.1016/j.bcp.2020.114122

Zalabani, S. M. E., Abdel-Sattar, E., Fathy, F. I., \& Shehab, N. G. (2003). Bioactive extracts of different organs of Cryptostegia grandiflora R. Br. grown in Egypt. Egyptian Journal of Biomedical Sciences, 11(233), 1-16. https://www.researchgate.net/publication/263809817 